\title{
A role for alternative splicing in circadian control of exocytosis and glucose homeostasis
}

\author{
Biliana Marcheva, ${ }^{1,5}$ Mark Perelis, ${ }^{1,2,5}$ Benjamin J. Weidemann, ${ }^{1,5}$ Akihiko Taguchi, ${ }^{1}$ Haopeng Lin, ${ }^{3}$ \\ Chiaki Omura, ${ }^{1}$ Yumiko Kobayashi, ${ }^{1}$ Marsha V. Newman, ${ }^{1}$ Eugene J. Wyatt, ${ }^{4}$ Elizabeth M. McNally, ${ }^{4}$ \\ Jocelyn E. Manning Fox, ${ }^{3}$ Heekyung Hong, ${ }^{1}$ Archana Shankar, ${ }^{2}$ Emily C. Wheeler, ${ }^{2}$ \\ Kathryn Moynihan Ramsey, ${ }^{1}$ Patrick E. MacDonald, ${ }^{3}$ Gene W. Yeo, ${ }^{2}$ and Joseph Bass ${ }^{1}$ \\ ${ }^{1}$ Department of Medicine, Division of Endocrinology, Metabolism, and Molecular Medicine, Northwestern University Feinberg \\ School of Medicine, Chicago, Illinois 60611, USA; ${ }^{2}$ Department of Cellular and Molecular Medicine, University of California at \\ San Diego, La Jolla, California 92093, USA; ${ }^{3}$ Department of Pharmacology, Alberta Diabetes Institute, University of Alberta, \\ Edmonton, Alberta T6G 2E1, Canada; ${ }^{4}$ Center for Genetic Medicine, Northwestern University, Chicago, Illinois 60611, USA
}

The circadian clock is encoded by a negative transcriptional feedback loop that coordinates physiology and behavior through molecular programs that remain incompletely understood. Here, we reveal rhythmic genome-wide alternative splicing (AS) of pre-mRNAs encoding regulators of peptidergic secretion within pancreatic $\beta$ cells that are perturbed in $\mathrm{Clock}^{-/-}$and Bmal1 ${ }^{-/-} \beta$-cell lines. We show that the RNA-binding protein THRAP3 (thyroid hormone receptor-associated protein 3 ) regulates circadian clock-dependent AS by binding to exons at coding sequences flanking exons that are more frequently skipped in clock mutant $\beta$ cells, including transcripts encoding Cask (calcium/calmodulin-dependent serine protein kinase) and Madd (MAP kinase-activating death domain). Depletion of THRAP3 restores expression of the long isoforms of Cask and Madd, and mimicking exon skipping in these transcripts through antisense oligonucleotide delivery in wild-type islets reduces glucose-stimulated insulin secretion. Finally, we identify shared networks of alternatively spliced exocytic genes from islets of rodent models of diet-induced obesity that significantly overlap with clock mutants. Our results establish a role for pre-mRNA alternative splicing in $\beta$-cell function across the sleep/wake cycle.

[Keywords: circadian clock; insulin secretion; exocytosis; alternative splicing; RNA sequencing; transcriptomics; THRAP3; MADD; CASK; SNAP25]

Supplemental material is available for this article.

Received March 5, 2020; revised version accepted June 10, 2020.

The circadian clock is an endogenous timing system that coordinates organismal physiology in anticipation of the sleep-wake cycle (Bass and Takahashi 2010; Asher and Schibler 2011; Bass 2012). At the molecular level, the clock is composed of basic helix-loop-helix transcription factors (TFs), in which activators in the forward limb (CLOCK and BMAL1) induce the transcription of their own repressors (PER1/2/3 and CRY1/2) in a cycle that repeats itself every $24 \mathrm{~h}$ (Balsalobre et al. 1998; Preitner et al. 2002; Liu et al. 2008; Bugge et al. 2012; Cho et al. 2012). The REV-ERB and ROR proteins form a reinforcing loop that modulates Bmal1 transcription. In turn, the core TFs induce robust amplitude in the rhythmic production of downstream PAR-bZIP TFs in liver and $\beta$ cells that play key roles in mammalian metabolism /Gachon et al. 2006;

\footnotetext{
${ }^{5}$ These authors contributed equally to this work. Corresponding author: j-bass@northwestern.edu Article published online ahead of print. Article and publication date are online at http://www.genesdev.org/cgi/doi/10.1101/gad.338178.120. Freely available online through the Genes \& Development Open Access option.
}

Tong et al. 2010; Nakabayashi et al. 2013). RNA sequencing analyses have shown that CLOCK/BMAL1 drive rhythmic expression of $10 \%-25 \%$ of all mRNAs within diverse mammalian tissues (Panda et al. 2002; Lowrey and Takahashi 2004; Hughes et al. 2009; Vollmers et al. 2009). Unique sets of genes oscillate across tissues due to interactions between CLOCK/BMAL1 and lineagedetermining factors (Lee et al. 2005; Perelis et al. 2015). Surprisingly, however, recent reports in liver have indicated that $\sim 70 \%$ of genes that display mRNA rhythmicity do not display oscillations in their corresponding intron-containing pre-mRNAs (Koike et al. 2012). Additionally, the zenith of CLOCK/BMAL1 chromatin binding does not correspond to the peak phase of mRNA accumulation for most target genes. These studies suggest that posttranscriptional regulation is a crucial component of

(c) 2020 Marcheva et al. This article, published in Genes \& Development, is available under a Creative Commons License (Attribution 4.0 International), as described at http://creativecommons.org/licenses/by/4.0/. 
circadian gene regulation (Koike et al. 2012; Menet et al. 2012; Green 2018).

Mounting evidence suggests that posttranscriptional RNA-processing events such as methylation, polyadenylation, and alternative splicing (AS) are linked to the circadian clock (Kojima et al. 2012; McGlincy et al. 2012; Fustin et al. 2013). AS, which enables a single genomic locus to produce multiple functionally distinct mRNAs in a tissue-, cell type-, and developmental stage-specific manner (Young et al. 1981; Vuong et al. 2016; Kim et al. 2018), is initiated upon the recruitment of RNA-binding proteins (RBPs) to consensus RNA motifs within regulatory elements of introns and exons of pre-mRNAs. RBPs then guide the oligomeric spliceosome complex to the correct sites for subsequent inclusion, exclusion, or skipping of exon cassettes to generate alternatively spliced transcripts. Rhythmic production of unique alternative mRNA splice isoforms from pre-mRNA has been shown to occur in plants, Drosophila, and mice (Sanchez et al. 2010; Hughes et al. 2012; McGlincy et al. 2012; Wang et al. 2018). Oscillating AS events have also been shown to be driven by both the internal core circadian clock and environmental timing cues such as temperature, which drives the rhythmic phosphorylation and function of serine-arginine (SR)-containing spliceosomal proteins as well as the splicing efficiency and stabilization of cold-inducible RNA-binding protein (Cirp) (Morf et al. 2012; Gotic et al. 2016; Preußner et al. 2017).

Evidence suggests that the clock regulates AS in neurons, where neurotransmitter release varies across the day/night cycle (Shinohara et al. 2002; Barber et al. 2016; Gizowski et al. 2016; Wang et al. 2018), raising the possibility that rhythmic AS may play a role in physiology. Genetic studies show that selective ablation of the molecular clock within pancreatic $\beta$ cells of adult mice induces diabetes due to severely impaired insulin secretion (Marcheva et al. 2010; Sadacca et al. 2011; Perelis et al. 2015; Petrenko et al. 2017). Clues to a role for rhythmic AS in $\beta$-cell function originated in RNA and ChIP sequencing studies in mouse and human pancreatic islets, which revealed that as many as $80 \%$ of rhythmic mRNAs and $82 \%$ of mRNAs differentially expressed in $\mathrm{Bmal1}^{-/-}$islets are not directly controlled by CLOCK/BMAL1, and are therefore regulated either transcriptionally or posttranscriptionally (Perelis et al. 2015).

Since the circadian transcriptome in islet cells is enriched for mRNAs encoding synapse-associated proteins that are established targets of AS, we sought here to test whether AS events are regulated by the clock through circadian RBP expression in islet cells. We used genomewide transcriptomics to quantify changes in AS events and expression in circadian controlled RNAs. We found that wild-type (WT) islets display rhythmic expression of RBPs and AS of mRNAs encoding protein regulators of peptidergic secretion, and that clock nullizygous $\beta$ cells display significantly increased exon skipping events in genes that control insulin secretion. We report a novel role for the circadian RBP THRAP3 in isoform selection within misspliced transcripts associated with insulin secretion in clock-deficient cells. In addition, we used live cell capacitance measurements to determine the level of impairment in exocytosis in new CRISPR-generated clock mutant $\beta$-cell lines as well as primary $\beta$ cells from pancreas-specific $\mathrm{Bmal1}^{-/-}$mice. Last, we identify an overlap between AS events that are disrupted in clock mutant $\beta$ cells and those identified in diet-induced obesity. Thus, we propose that RNA missplicing in $\beta$ cells contributes to the etiology of diabetes mellitus in conditions of circadian disruption.

\section{Results}

\section{Circadian control of alternative splicing in pancreatic islets throughout the day}

To determine whether posttranscriptional alternative premRNA splicing in pancreatic islets is influenced by circadian time, we first assessed genome-wide AS events from WT mouse islets cultured ex vivo and sampled in triplicate at 4$\mathrm{h}$ intervals for $48 \mathrm{~h}$ following synchronization by a $1-\mathrm{h} 10$ $\mu \mathrm{M}$ forskolin shock (Perelis et al. 2015) (GSE69889) (see schematic in Fig. 1A). We used rMATS (replicate multivariate analysis of transcript splicing) (Shen et al. 2014) to identify and quantify the following types of AS events: skipped exons (SE), alternative $3^{\prime}$ and $5^{\prime}$ splice sites (A3SS and A5SS), and mutually exclusive exons (MXE) (Fig. 1A). To compare AS events across time, we first collected RNA sequencing (RNA-seq) reads in our data that uniquely aligned to exon-exon junctions annotated within the reference genome that were commonly assigned as AS events in all time points that had changes in percent-spliced in $(\psi)$ values reflecting exon inclusion in at least half of all averaged time points. The ensemble of AS events in our data included 11,400 SEs, 2251 A3SSs, 1297 A5SSs, and 1689 MXEs across 6520 unique genes. To establish the trajectories of AS events throughout the time series to assess rhythmic AS across the day, we calculated $\psi$ for all common AS events from each of the three replicate samples for each time point and identified statistically significant (adjusted $P$-value < 0.05) oscillations in $\psi$ using JTK_cycle (Hughes et al. 2010), allowing for period lengths of 20, 24, or $28 \mathrm{~h}$. This analysis revealed a total of 257 oscillatory AS events, consisting of 172 SE, 44 A3SS, 20 A5SS, and 21 MXE events across 241 unique genes (Fig. 1A; Supplemental Table S1), which collectively displayed a bimodal distribution in peak phases occurring 44 and $52 \mathrm{~h}$ after shock (Fig. 1B). Sashimi plots, which show reads mapping across splice junctions to quantify exon inclusion levels, are shown across the circadian day to demonstrate rhythmic AS for Golgb1, which encodes a Golgi-associated and vesicle tethering factor (Fig. 1C; Supplemental Fig. S1A). Rhythmic AS for other representative genes is shown by plotting inclusion level differences for cassette exons across the circadian day in the splicing factor Srrm2 and the synaptic vesicle cycle-associated GTPase Dnm1 (Supplemental Fig. S1A). These data establish for the first time that the molecular clock regulates rhythmic AS throughout the day in the pancreatic islet, a peripheral cell type.

Given that the islet circadian transcriptome is enriched for mRNAs encoding trafficking and synapse-associated 

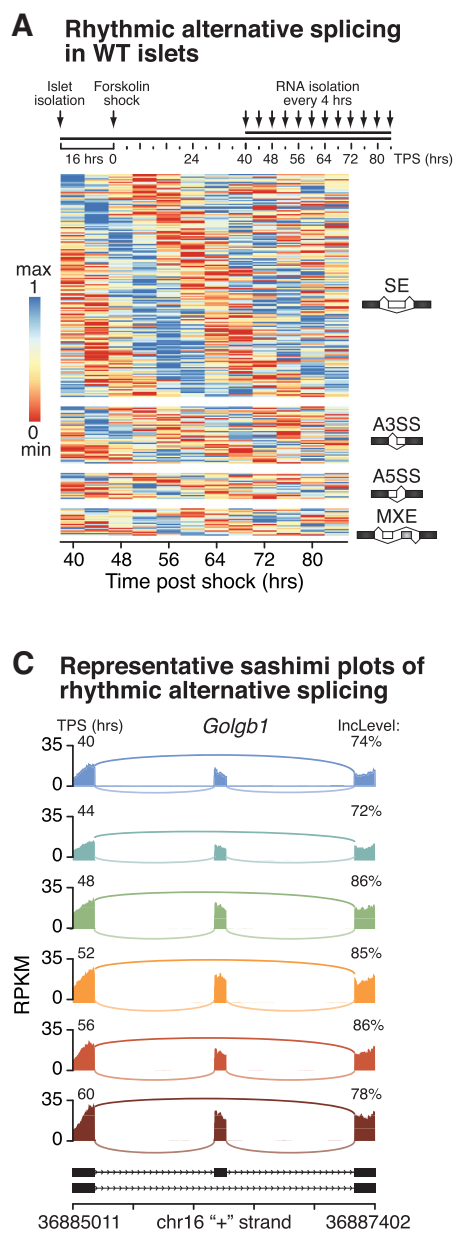

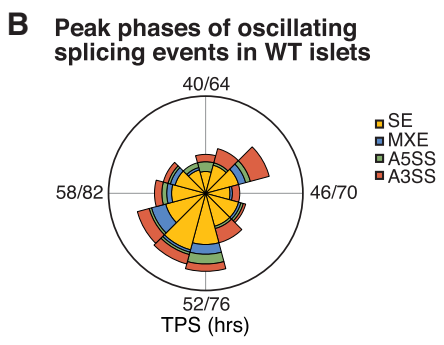

D Enrichment of trafficking and secretion pathways in rhythmically spliced gene sets

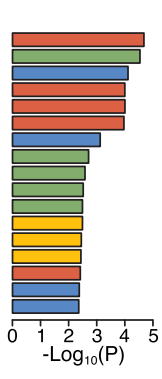
Term Prot. modification by protein conjugation/removal RNA polymerase II transcription
Postsynaptic membr. neurotrans. receptor reg. Postsynaptic memb
Exocytic process Spontaneous synaptic transmission RNA splicing Protein maturation
Peptidyl-glutamic acid modification Negative regulation of protein catabolic process Misfolded/incompletely synthesized protein control Regulation of histone deacetylation
DNA recombination Positive reg. of G2/M transition of mitotic cell cycle Microtubule cytoskeleton organization DNA-templated transcription initiation
DNation

- Trafficking and synapse TTranscription, signaling, and splicing
a Protein modification and regulation 口DNA and chromatin

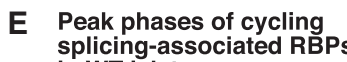
in WT islets

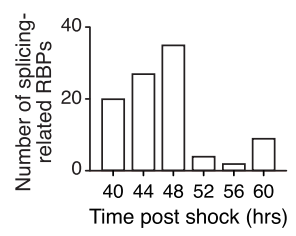

Figure 1. Circadian control of alternative splicing in pancreatic islets throughout the day. (A) Schematic of ex vivo experimental design for RNA isolation in forskolin-synchronized mouse islets. RNA was isolated every $4 \mathrm{~h}$ for $48 \mathrm{~h}$ starting $40 \mathrm{~h}$ after forskolin shock. TPS (hours), time after shock (hours) ( $n=3 /$ timepoint). Heatmap representing rhythmically spliced genes (skipped exons [SE], alternative $3^{\prime}$ and $5^{\prime}$ splice sites [A3SS and A5SS], and mutually exclusive exons [MXE]) every $4 \mathrm{~h}$ over the course of $48 \mathrm{~h}$ in forskolinsynchronized oscillating WT islets. $(B)$ Radial histogram showing the number of splicing events of each type with peak psi occurring within each period length-adjusted phase, with the radius corresponding to 40 splicing events. (C) Representative sashimi plots show time of day-dependent alternative splicing of Golgb1 every $4 \mathrm{~h}$ across $24 \mathrm{~h}$ (starting $40 \mathrm{~h}$ after forskolin shock), with the exon inclusion level indicated at each time point. (D) Pathway analyses reveal significant enrichment of trafficking and secretion pathways within alternatively spliced gene sets. $(E)$ Peak phase in expression of cycling RNA-binding proteins within the GO ontology term "RNA splicing." proteins known to be regulated by AS in neuronal tissues, we hypothesized that similar pathways might emerge within circadian-controlled alternatively spliced transcripts. Indeed, interrogation of functional pathways included in KEGG (Kyoto Encyclopedia of Genes and Genomes), GO (gene ontology), and reactome databases using Metascape (Tripathi et al. 2015) revealed that genes with oscillatory splicing events are over-represented in trafficking and synapse pathways (Fig. 1D), including endocytosis (i.e., Dnm1, Pip5k1a, Vps25, Rab11a, and Smap2), spontaneous synaptic transmission (i.e., Rims2, Mtmr2, and App), and exocytic processes (i.e., Grik5, Snap47, Vps11, and Synj1). Several pathways and gene targets regulating transcription and posttranscriptional processing were also identified (Fig. 1D), including the transcript for splicing factor SRRM2 (Supplemental Fig. S1A). Interestingly, comparison of rhythmically spliced transcripts (from Fig. 1A) and rhythmically expressed transcripts (from Perelis et al. 2015) revealed that while only $34 \%$ of rhythmically spliced transcripts overlapped with rhythmically expressed mRNAs, both were enriched for gene sets important for synaptic and secretory pathways (Supplemental Fig. S1B).

Since AS occurs as a consequence of interactions between RBPs and splicing regulatory elements in pre-
mRNAs, we next interrogated the islet transcriptome for rhythmically expressed RBPs and identified 296 oscillating transcripts encoding RBPs (Supplemental Fig. S1C; Supplemental Table S2). We identified oscillation of RBPs such as Nono and Adarb1, which have been implicated in regulating circadian RNA transport and editing, respectively (Terajima et al. 2017; Benegiamo et al. 2018). Of note, of the 296 rhythmic RBPs, 99 have shown to been associated with splicing (Fig. 1E; Supplemental Table S2), including Thrap3 (Lande-Diner et al. 2013). We further observed that rhythmic RBPs, including the splicing-associated RBPs, displayed peak phases of expression $\sim 44-48 \mathrm{~h}$ after shock (Fig. 1E; Supplemental Fig. S1C), which overlapped with the first peak in splicing (Fig. 1B) and the zenith in insulin secretion (Perelis et al. 2015). Conversely, the trough of RBP expression (Fig. 1E; Supplemental Fig. S1C) coincided with the second peak in splicing $\sim 52-$ $56 \mathrm{~h}$ after shock (Fig. 1B) and was in anticipation of the nadir in insulin secretion (Perelis et al. 2015).

Generation of cell models for analysis of BMAL1 and CLOCK alternative splicing and function

Given that alternative splicing of mRNAs encoding key exocytotic and trafficking factors varies across the day in 
islet cell clusters (Fig. 1D), and that both clock-controlled expression and AS are cell type-specific (Young et al. 1981; Vuong et al. 2016), we next sought to determine the specific role of the $\beta$-cell molecular circadian clock in regulating the synthesis and processing of protein-coding messenger RNAs. To do so, we first generated clonal isogenic $\beta$-cell lines lacking a functional clock $\left(\mathrm{Bmal1}^{-/-}\right.$or $\left.\mathrm{Clock}^{-/-}\right)$ that recapitulate physiologic features of glucose-responsive insulin secretion. We used CRISPR/Cas9 gene editing and homology-directed repair (HDR) in mouse $\beta$-TC6 cells to establish Bmal1 and Clock nullizygous $\beta$ cells harboring premature stop codons that lead to disruption of exons encoding the bHLH DNA-binding domains (Supplemental Fig. S2A). Quantitative real-time PCR and Western blot screening of individual clones identified desired cell lines lacking functional Bmal1 and Clock mRNA and protein, as well as decreased expression of their downstream target Rev-erba (Supplemental Fig. S2B,C). To confirm functional loss of the $\beta$-cell core molecular clock, we transduced $\mathrm{Bmal1}^{-1-}, \mathrm{Clock}^{-/-}$, and control $\beta$-cell lines with a lentivirus encoding a Per2 promoter fragment containing consensus binding sites for core circadian TFs immediately upstream of the firefly Luciferase (Luc) gene that is sufficient to drive circadian bioluminescence rhythms in mammalian cells (Supplemental Fig. S2D; Liu et al. 2008). Whereas control $\beta$-cell lines transduced with the Per2-dLuc reporter displayed robust circadian bioluminescence rhythms following synchronization by exposure to a 24-h temperature cycle that mimics the endogenous body temperature rhythm (Buhr et al. 2010; Saini et al. 2012), PER2-dLUC failed to oscillate in $\mathrm{Bmal1}^{-1-}$ and $\mathrm{Clock}^{-/} \beta$ cells, indicating a loss of the core circadian network function in these cells (Supplemental Fig. S2D). Consistent with $\beta$-cell-specific loss of clock function, these $\mathrm{Bmal1}^{-/-}$and $\mathrm{Clock}^{-/-} \beta$-cell lines had impaired nutrient and nonnutrient secretagogue-induced insulin secretion following exposure to either glucose or potassium chloride, respectively (Supplemental Fig. S2E; Marcheva et al. 2010; Perelis et al. 2015). Importantly, these $\mathrm{Bmal1}^{-/-}$ and $\mathrm{Clock}^{-1-} \beta$-cell lines have secretory phenotypes that are shared with pancreas-specific Bmal1 mutant mice (Marcheva et al. 2010; Sadacca et al. 2011; Perelis et al. 2015). Here, we also show a similar loss of glucose-responsive insulin secretion in pancreas-specific Clock knockout mice. Ablation of CLOCK expression specifically in pancreatic islets was confirmed by immunofluorescent staining (Supplemental Fig. S3A) and did not alter locomotor activity, circadian period length, feeding rhythm, or body weight (Supplemental Fig. S4). Similar to pancreas-specific loss of BMAL1, we observed significant hyperglycemia without a concomitant increase in insulin (Supplemental Fig. S3B,C), and PdxCre; Clock ${ }^{f l x / f l x}$ mice were glucose intolerant and displayed reduced insulin secretion following a glucose challenge compared with their littermate controls (Supplemental Fig. S3D). Finally, islets isolated from pancreas-specific Clock KO mice also secreted significantly less insulin in response to both glucose and $\mathrm{KCl}$, an insulin secretagogue that causes direct $\beta$-cell depolarization, despite no change in intracellular insulin content, consistent with observations in CRISPR cell lines (Supple- mental Fig. S3E). Together, these findings in vivo and in cell lines are the first to show that both BMAL1 and CLOCK TFs are required for appropriate control of stimulus-secretion coupling within $\beta$ cells and prompted us to interrogate genome-wide transcription and processing of mRNAs underlying the circadian control of insulin secretion in pancreatic $\beta$ cells versus in a heterogeneous islet population. Our results demonstrate a cell-autonomous requirement for molecular clock components in $\beta$-cell function.

\section{BMAL1 and CLOCK control shared exocytic networks regulated by alternative splicing}

To first identify the repertoire of genes specifically regulated by both BMAL1 and CLOCK in $\beta$ cells and to ultimately determine whether circadian regulation of RNA processing may also contribute to secretory defects in clock mutant $\beta$ cells, we initially performed RNA sequencing (RNA-seq) comparing polyadenylated mRNAs isolated from $\mathrm{Bmal1}^{-/-}, \mathrm{Clock}^{-/-}$, and WT control $\beta$ cells. We identified altered expression of 3035 genes in $\mathrm{Bmal1}^{-/-}$cells and 1606 genes in Clock $^{-/-}$cells $\left(\log _{2} \mathrm{FC}\right.$ $>1$, FDR $<0.01$ ) (Fig. 2A). Among these differentially expressed genes, we focused on the 815 mRNAs that were differentially expressed in both $\mathrm{Clock}^{-/-}$and $\mathrm{Bmal1}^{-/-}$ cells, as they are more likely to underlie the common secretory phenotypes observed in these two lines (Supplemental Table S3). Importantly, 79\% (640/815) of the commonly differentially expressed genes displayed common directionality (up-regulated or down-regulated in both), including a large number of genes related to secretory processes (Fig. 2A), suggesting a high degree of overlap of target genes regulated by both core clock activators, as opposed to being CLOCK or BMAL1 targets independent of the core clock network. Among these commonly differentially expressed mRNAs, $21 \%(136 / 640)$ were upregulated while $79 \%$ (504/640) were down-regulated, consistent with inhibition of a transcription activation complex (Fig. 2A; Supplemental Fig. S5A). To identify the functional $\beta$-cell gene networks regulated by both CLOCK and BMAL1, we tested for over-representation of defined KEGG, GO, and reactome pathways amongst the genes that were commonly changed in both CLOCK and BMAL1 mutant cell lines using Metascape (Tripathi et al. 2015). Consistent with inhibition of insulin secretion, the 504 down-regulated mRNAs common to both CLOCK and BMAL1 knockout cells were enriched for genes with annotated functions related to G-protein and ion channel activation, synaptic processes, and regulation of hormone secretion (Supplemental Fig. S5B). Among these were neurotransmitter and hormone receptors mediating responses to somatostatin (Sstr1, Sstr3, and Sstr5), acetylcholine (Chrna3 and Chrna4), norepinephrine (Adra2b), dopamine (Drd2), glycine (Glra1), and glutamate (Gria4), as well as voltage-gated calcium (Cacng5 and Cacna2d4), sodium (Scn1b), and potassium channels (Kcne1, Kcnh3, Kcnj12, Kcnk1, Kcnma1, and Kcnq2). mRNAs encoding proteins mediating the synthesis or downstream effectors of second messenger signals 
initiated by membrane-bound receptors such as calcium, $3^{\prime}, 5^{\prime}$ cyclic adenosine monophosphate (cAMP), and diacyl glycerol were also inhibited in clock mutant cells (Syt2, Syt16, Adcy5, Rgs4, and Dgkb). Last, clock mutant cells displayed altered expression of mRNAs encoding proteins regulating organelle localization (Rab15 and Myrip) and synaptic vesicle priming and exocytosis $(D o c 2 b$ and Cadps2). These changes in the transcriptomes of CLOCKand BMAL1-deficient cells suggest altered expression and function of proteins coupling nutrient sensing to the regulated release of insulin. Indeed, electrophysiologic analyses revealed that Bmal1 mutant $\beta$-cell lines and primary mouse $\beta$ cells from PdxCre;Bmal1 ${ }^{f l x / f l x}$ mice display reduced rates of exocytosis following direct depolarization as indicated by reduced capacitance in the circadian mutant $\beta$-cell lines and mouse $\beta$ cells (Fig. 2B). The set of commonly differentially expressed genes also included mRNAs encoding synaptic membrane-associated proteins that are functionally regulated by AS in neurons (Snap25, Nrxn2, and Erc2), which prompted us to next interrogate the impact of disruption of the molecular clock on posttranscriptional pre-mRNA AS in $\beta$ cells.

Given that synchronized WT islets display rhythmic AS (Fig. 1) and that clock control of peptide secretion in pancreatic $\beta$ cells is similar to that in neurons, we next assessed genome-wide AS patterns in Clock and Bmal1 mutant $\beta$ cells. We hypothesized that circadian control of RNA processing may also contribute to cell type-specific circadian gene regulation and insulin secretion in the $\beta$ cell. We used rMATS to quantify AS events in Clock and Bmal1 mutant cell lines relative to WT. Considering both intron spanning and exonic reads, we detected 1453 AS events in Bmal1 mutant cells (FDR $<0.05, \psi>0.1$ ) consisting of 1018 skipped exons (SE), 174 mutually exclusive exons (MXE), 134 alternative $3^{\prime}$ splice sites (A3SS), and 127 alternative $5^{\prime}$ splice sites (A5SS). In Clock mutant cells, we detected 710 AS events, of which 492 were SE, 105 were MXE, 63 were A3SS, and 50 were A5SS events. Applying the same filtering approach as for mRNA expression, we identified 101 AS events within 95 annotated genes that were common and displayed similar directionality in both Bmal1 ${ }^{-/-}$and Clock ${ }^{-/-}$cells (Fig. 2C,D; Supplemental Table S4). A majority of the common AS events were SE (93), with the remaining as MXE (four) and A3SS (four) events (Fig. 2C). Only four of these 95 alternatively spliced genes were included among the 640 differentially expressed mRNAs (Supplemental Fig. S5D), suggesting that changes in AS and mRNA abundance are regulated by distinct mechanisms downstream from the molecular clock. Differentially spliced mRNAs encoded proteins known to mediate cellular events important for insulin vesicle transport and exocytosis, such as cytoskeletal and motor proteins (Mapt, Arhgap21, Myo5a, Kif16b, and $D \operatorname{ctn} 1$ ), vesicle membrane constituents (Erc2, Ap1s2, and Sec31a), synaptic vesicle-associated proteins (Snap25), and kinases and GTPases responsible for posttranslational modifications to the secretory apparatus (Cask and Madd) (Fig. 2D; Supplemental Fig. S5C).

Previous studies have used FACS-sorting to uncover distinct circadian transcriptional profiles of $\alpha$ and $\beta$ cells, re- vealing that exocytic genes in these two cell populations within the islet oscillate in distinct phases (Petrenko et al. 2017). To specifically test whether $\alpha$ - and $\beta$-cell types display differences in peaks of AS events across the day, we examined rhythmic patterns of AS events in FACS-sorted $\alpha$ and $\beta$ cells collected every $4 \mathrm{~h}$ across a 24 -h circadian cycle by performing rMATS analyses on this published data set (GSE95156), as we did with the synchronized islets in Figure 1A. Indeed, we found that a majority of the transcripts that displayed altered splicing in the clock-deficient $\beta$ cells (Fig. 2D), but that were not identified as statistically rhythmic in whole islets, exhibited peak exon inclusion at distinct times of day in a versus $\beta$ cells (Fig. 2E). To independently determine whether the differentially spliced transcripts identified in the clock mutant $\beta$-cell lines (Fig. 2D) displayed rhythmicity in a pure WT $\beta$-cell population, we synchronized WT $\beta$-TC6 cells (Supplemental Fig. S5E) and performed targeted qPCR analysis of representative differentially spliced (SE) transcripts, including the secretion-related genes Cask, Madd, Dock11, and Dctn1. We observed patterns of rhythmic exon inclusion in these key targets, which exhibit high degrees of AS under control of CLOCK/BMAL1 (Fig. 2F; Supplemental Fig. S5F), indicating that splicing events that are perturbed by clock mutation display rhythms in a pure population of $\beta$ cells. Together these data reveal a connection between the activating limb circadian TFs and rhythmic splicing in pancreatic $\beta$ cells.

\section{Thyroid hormone receptor associated protein 3 (THRAP3) regulates circadian clock-dependent alternative splicing}

Given our observation that rhythmic splicing occurs under the control of core circadian transcription factors (TFs), we next sought to examine how the clock TFs regulate AS in pancreatic $\beta$ cells by examining RBPs displaying rhythmic expression in islet cells (Supplemental Table S2). Identification of rhythmic expression of the gene encoding the RBP THRAP3 (thyroid hormone receptor-associated protein 3) (Supplemental Fig. S6A ) was of particular interest since THRAP3 has been shown to regulate AS by interacting with splicing factors (Nakatsuru et al. 1989; Yarosh et al. 2015). It also binds CLOCK/BMAL1 to regulate rhythmic transcription (Lande-Diner et al. 2013) and metabolic TFs such as PPAR $\gamma$ recruit THRAP3 to chromatin (Choi et al. 2014). To determine whether THRAP3 binds to differentially spliced transcripts in clock mutant $\beta$-cell lines, we performed enhanced UV cross-linking and immunoprecipitation (eCLIP), followed by sequencing analysis (Van Nostrand et al. 2016) in two replicate WT and Bmal1-/- lysates. Briefly, THRAP3-RNA complexes were immunoprecipitated, and ribonucleoprotein (RNP) complexes within the expected size range were isolated following electrophoresis and transfer to nitrocellulose membranes. For each IP replicate, a corresponding input lysate was processed to isolate a size-matched input RNA sample, comprising RNAs within the background set of RNPs similarly sized to THRAP3 complexes. We note that size matching to input is necessary in order to 
control for differences in RNA expression levels across the genome. Illumina sequencing libraries were then generated from both WT and Bmal1-/- $\beta$-cell-derived IP and input RNA (Fig. 3A, see Materials and Methods). This approach allowed us to compare abundance of THRAP3-RNA complexes relative to size-matched protein-bound RNA input within each genotype, thus controlling for alterations in total protein-bound RNA abundance that may occur between genotypes. We found that THRAP3 binding in the $\mathrm{Bmal1}^{-/-}$cells was enriched relative to $\mathrm{Bmal1}^{-1-}$ sizematched input specifically within coding exons flanking exons that were skipped more frequently in $\mathrm{Bmal1}^{-/-}$cells (Fig. 3A), but not in regions surrounding exons that were preferentially retained in clock mutant cells (Supplemental Fig. S6B), as indicated by increased normalized sequencing reads in THRAP3 IP versus size-matched input control at the exons immediately up-stream of and down-stream from the skipped exon (Fig. 3A). In contrast, we did not observe enrichment of THRAP3 IP sequencing reads relative to input in WT cells in these regions (Fig. 3A), suggesting that THRAP3 displays increased occupancy along these regions in $B$ mal1 $1^{-1-}$ cells compared with WT. This pattern of enrichment of THRAP3 IP reads com- pared with input can also be visualized within individual genes containing clock-dependent SE events, including Cask, Madd, and Dctn1 (Fig. 3B; Supplemental Fig. S6C). Given that THRAP3 displays increased binding at exons flanking differentially spliced cassette exons in $\mathrm{Bmal1}^{-/-}$ $\beta$ cells, we hypothesized that siRNA-mediated depletion of Thrap3 in Bmal1-/- $\beta$ cells would lead to increased inclusion of the skipped exons. Indeed, we observed increased retention of skipped cassette exons in Madd, Cask, and Dock 11 by $\sim 1.5$-fold in Bmal1 $^{-/-}$cells expressing Thrap3 siRNA (Fig. 3C; Supplemental Fig. S6D), without altering cassette exon inclusion in WT cells (Supplemental Fig. S6E). However, THRAP3 depletion did not restore inclusion of the cassette skipped in Dctn1, which may be regulated by other clock-controlled RBPs (Supplemental Fig. S5G). This data indicates that increased THRAP3 occupancy at these RNAs in Bmal1-/cells drives exon skipping.

Having established a role for THRAP3 in AS in $\mathrm{Bmal1}^{-/-}$ cells, we next hypothesized that THRAP3 may contribute to the rhythmic AS in WT islets. To test whether THRAP3 was enriched within exons flanking rhythmic cassette exons in a time of day-dependent manner, we examined SE
A

Overlap of differentially expressed genes in

$B$ mal1 $1^{-1}$ and Clock ${ }^{-1} \beta$-cells

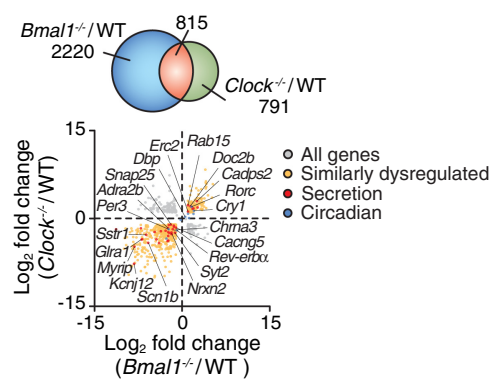

C

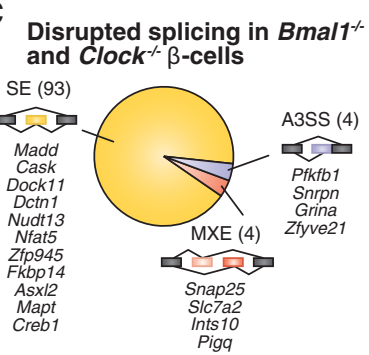

E

Distinct peak phases of clockdependent alternative splicing events in a vs $\beta$ cells

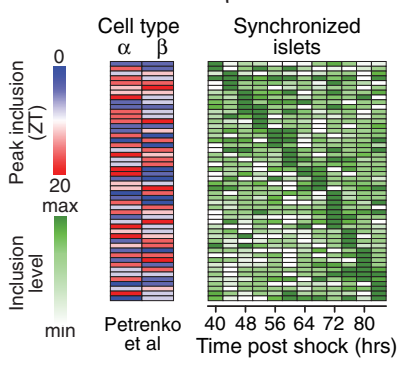

B

Reduced exocytosis in clock mutant $\beta$-cell lines and primary $\beta$-cells

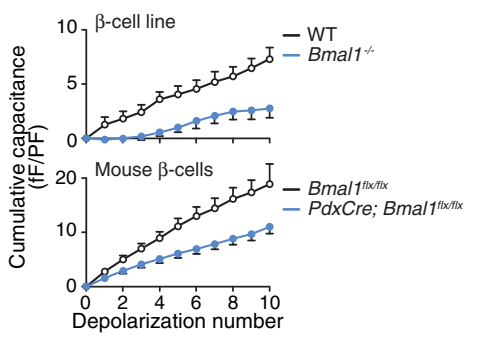

D Overlap in splicing events in $\mathrm{Bmal1}^{-1 /}$ and Clock $/ 1-$-cells

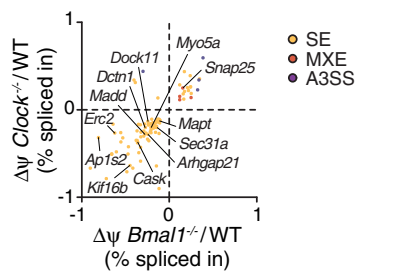

F

Rhythmic splicing of events identified in clock mutant $\beta$-cells

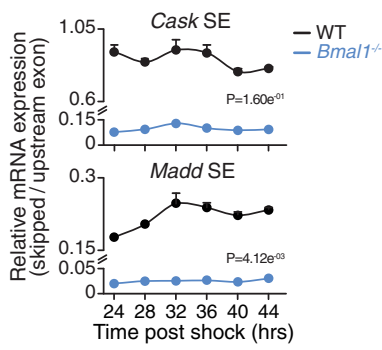

Figure 2. Ablation of both BMAL1 and CLOCK disrupts splicing within gene networks important in vesicle trafficking and exocytosis. $(A, t o p)$ Venn diagram of overlapping differentially expressed genes identified by RNA sequencing in $\mathrm{Bmal1}^{-/-}$and $\mathrm{Clock}^{-/-}$ $\beta$-cell lines compared with control cell line. (Bottom) Scatter plot depicts all differentially expressed genes, highlighting secretion and circadian genes with a strong correlation between directionality of gene expression changes between $\mathrm{Bmal1}^{-/-}$and $\mathrm{Clock}^{-/} \beta$ cell lines. $(B)$ Capacitance measurements in Bmal1-/- $\beta$-cell lines $(n=13-17$ cells per genotype) and $\beta$ cells from $P d x C r e ; B m a l 1^{f l x / f l x}$ mouse islets $(n$ = 4-5 mice per genotype, 7-16 cells per mouse) compared with controls. (C) Splicing analysis reveals differential alternative splicing events (skipped exons [SE], mutually exclusive exons [MXE], and alternative $3^{\prime}$ splice sites [A3SS]) common in both $\mathrm{Bmal1}^{-/-}$and Clock $^{-/-} \beta$-cell lines. Representative genes are listed below each category. $(D)$ Scatter plot depicts alternatively spliced genes common to both $\mathrm{Bmal1}^{-/-}$and Clock $^{-l-} \beta$-cell lines, highlighting strong correlation of directionality between Bmal1 ${ }^{-1-}$ and $\mathrm{Clock}^{-1-} \beta$ cell lines. (E) Zeitgeber time (ZT) of peak inclusion in sorted $\alpha$ and $\beta$ cells from islets (left) (Petrenko et al. 2017) and patterns of mean $\psi$ scores across two 24-h timescales for skipped exon events identified in clock mutants in synchronized islets (right). $(F)$ Rhythmic splicing events identified via qPCR in forskolin-synchronized WT and Bmal1-/- $\beta$-cell lines $(n=3 /$ timepoint $)$. RNA was isolated every $4 \mathrm{~h}$ across $24 \mathrm{~h}$ (starting $24 \mathrm{~h}$ after forskolin shock). Skipped exon expression was normalized to a neighboring (nonspliced) exon, and evaluation for rhythmicity performed by JTK_CYCLE (adjusted $P$-value shown). 


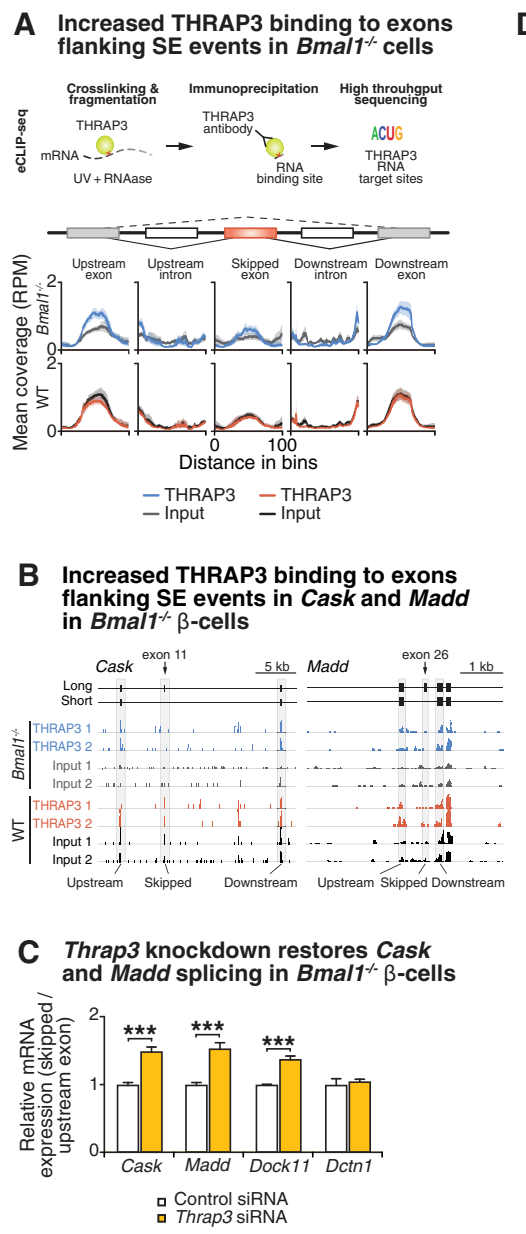

A Increased THRAP3 binding to exons

C Thrap3knockdown restores Cask

events displaying significant changes between the two time points containing the largest number of rhythmic splicing events (44 and $56 \mathrm{~h}$ after shock). Similar to regions containing SEs identified in Bmal1 ${ }^{-/-}$cells, exons frequently skipped at $44 \mathrm{~h}$ after shock displayed THRAP3 enrichment relative to input RNA in Bmal1 ${ }^{-/-}$cells at the exons flanking the skipped exon cassette (Supplemental Fig. S6F), indicating that the molecular clock regulates its deposition on RNA in proximity to clock-controlled cassette exons.

In addition to its role as an RNA-binding protein, THRAP3 can also be recruited to chromatin by CLOCK/ BMAL1 and PPAR $\gamma$ (Lande-Diner et al. 2013; Choi et al. 2014). To determine whether loss of BMAL1 impacts THRAP3 chromatin binding in $\beta$ cells, we performed THRAP3 chromatin immunoprecipitation sequencing (ChIP-seq). We found a greater number of THRAP3 ChIP-seq peaks in Bmal1-l- cells $(12,988)$ compared with WT cells (6167); however, THRAP3 occupancy at peaks identified in each genotype was tightly correlated between genotypes (Supplemental Fig. S7A). Next, since THRAP3 ChIP-seq peaks occurred in 57\% (533/942) of genes that were alternatively spliced in $\mathrm{Bmal1}^{-/-}$cells, and since THRAP3 is corecruited to target genes by collaborative TFs (Lande-Diner et al. 2013; Choi et al.
2014), we compared TF motifs that were enriched within the promoters of the following gene sets: (1) genes with THRAP3 ChIP-seq peaks in their promoters, (2) genes alternatively spliced in $\mathrm{Bmal1}^{-/-} \beta$ cells, and (3) genes with rhythmic AS events in synchronized islets. Motif analysis within THRAP3-bound promoters of rhythmically spliced genes revealed enrichment of circadian E-box, bZIP, and ETS motifs (Fig. 3D; Fang et al. 2014). Notably, mRNAs encoding several TFs predicted by Homer to bind these motifs, including E-box-binding bHLH proteins Usf2, Tfe3, and Maz, bZIP protein c/un, and ETS family proteins Elk1 and Elf1, were up-regulated in clock mutant $\beta$ cells, suggesting that they may be responsible for clockdependent THRAP3 recruitment to target genes (Supplemental Fig. S7B). Moreover, THRAP3 binding density, computed by plotting normalized ChIP-seq reads along indicated genomic regions, was enriched in the vicinity of previously published CLOCK and BMAL1 ChIP-seq peaks occurring within promoters of $\beta$-cell genes (Supplemental Fig. S7C). However, THRAP3 was not enriched in binding within promoter ChIP-seq peaks for the noncircadian $\beta$ cell lineage determining factor PDX1 (Supplemental Fig. S7C; Perelis et al. 2015). Together these data suggest that recruitment of THRAP3 by the core molecular clock and coregulated TFs is coupled to alternative splicing. 


\section{Alternative splicing of Cask and Madd directly} modulates $\beta$-cell insulin secretion

Given that Cask and Madd display among the highest degrees of exon inclusion level difference in $\mathrm{Bmal1}^{-1-}$ and Clock $^{-/-}$cells compared with WT (Fig. 2C,D), and that THRAP3 is enriched at exons flanking the skipped exon in Cask and Madd in Bmal1 ${ }^{-/-}$cells (Fig. 3B), we sought to determine whether missplicing of Cask and Madd contributes to impaired $\beta$-cell function in $\mathrm{Bmal1}^{-1-}$ cells. Cask had an $\sim 36 \%$ reduction in inclusion of exon 11 in both $\mathrm{Bmal1}^{-1-}$ and Clock ${ }^{-1-}$ cells (Fig. 4A), and Madd displayed a $28 \%$ reduction in exon 26 in both $\mathrm{Bmal1}^{-/-}$and Clock $^{-1-}$ cells (Fig. 4C). CASK was of particular interest as a member of the membrane-associated guanylate kinase (MAGUK) protein family that helps initiate assembly of the presynaptic secretory machinery. CASK is involved in exocytosis of neurotransmitters in the brain (Atasoy et al. 2007) and of insulin in the endocrine pancreas (Suckow et al. 2008; Wang et al. 2015). Furthermore, Uniprot and Interpro annotations show that exon 11 of Cask, which is skipped more frequently in the circadian mutants, encodes a domain that facilitates interactions with synaptic membrane proteins (Fig. 4A; Chetkovich et al. 2002; Lee et al. 2002; Roh et al. 2002). Madd, a splice variant of the insulinoma-glucagonoma clone 20 (IG20) gene, contains a single nucleotide polymorphism associated with human type 2 diabetes, and Madd knockout mice display hyperglycemia and impaired insulin secretion (Li et al. 2014). Exon 26 of Madd, which is skipped more often in the clock mutants, encodes 58 amino acids upstream of its death domain, which inhibits caspase activation (Fig. 4C; Kurada et al. 2009). To examine the impact of the increased abundance of the short isoforms of Cask and Madd transcripts in Bmall and Clock mutant $\beta$ cells, we generated antisense oligonucleotides (ASOs) targeting the exons that were skipped more frequently in the mutants. ASOs are short single-stranded segments of DNA that can affect expression of alternatively spliced protein isoforms by initiating exon skipping or inclusion by masking silencing sites during splicing. We treated WT islets with control and targeting ASOs against Cask and Madd and observed $\sim 81 \%$ and $\sim 90 \%$ reduction in inclusion of Cask exon 11 and Madd exon 26 mRNA, respectively, relative to a nontargeting control ASO (Fig. $4 \mathrm{~B}, \mathrm{D})$, while the ASOs did not alter expression of upstream exons 1 and 3 in Cask and Madd, respectively (Fig. 4B,D). Notably, islets treated with targeting ASOs against both Cask and Madd displayed significantly reduced glucose-stimulated insulin secretion compared with control ASO-treated islets (by $\sim 40 \%$ ) (Fig. 4B,D), suggesting that clock-regulated splicing of these transcripts supports $\beta$-cell function. Thus, these results demonstrate that mimicking exon skipping through the use of ASOs, which promotes expression of the short isoforms of these two genes whose splicing is controlled by the circadian clock, reduces glucose-stimulated insulin secretion, suggesting that missplicing of these mRNAs contributes to secretory failure in the setting of circadian disruption.
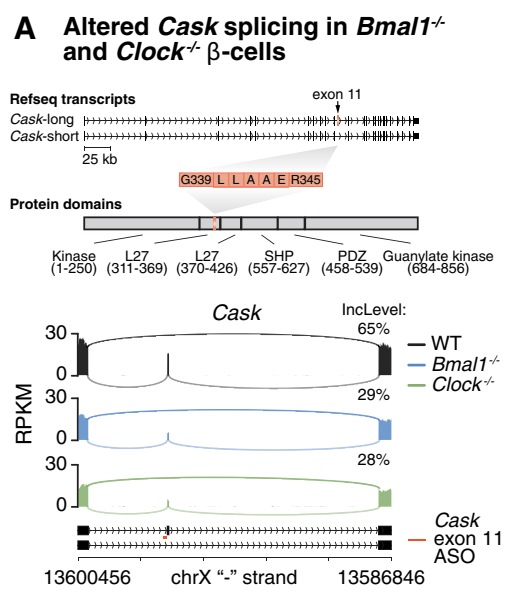

B Disrupted Cask splicing alters insulin secretion in WT islets
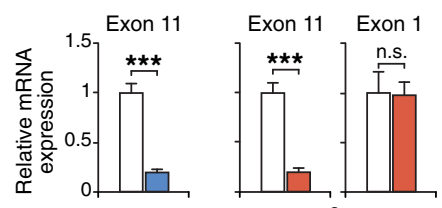

ㅁ WT
amal1

¿Control ASO Cask exon 11 ASO

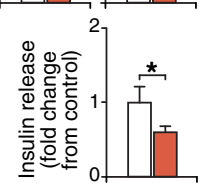

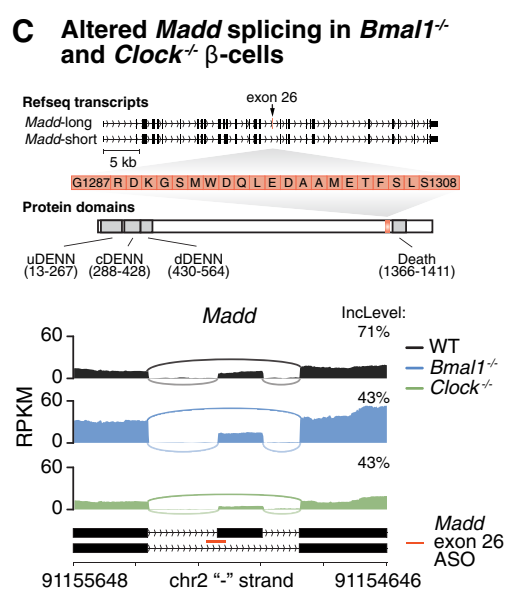

D Disrupted Madd splicing alters insulin secretion in WT islets
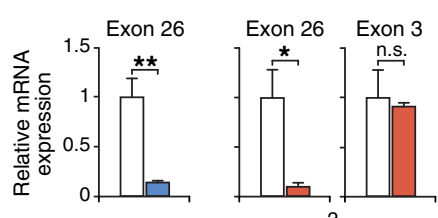

ㅁT
․mal1

-Control ASO \Madd exon 26 ASO

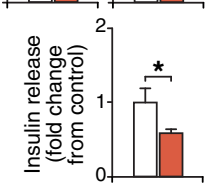

Figure 4. Skipped exons within Cask and Madd in circadian mutant $\beta$ cells impair insulin secretion. (A) Refseq transcripts depict the "long" and "short" (i.e., skipping exon 11) isoforms of Cask. Exon 11 encodes amino acids 339-345, which InterPro annotates as part of the C-terminal L27 domain. Sashimi plots of the differentially spliced Cask gene in Bmal1-/- and Clock ${ }^{-/-} \beta$-cell lines. (B) Expression of Cask skipped exon 11 or nontargeted exon 1 in WT $(n=7)$ and Bmal1 $^{-1-}(n=6) \beta$ TC6 cells and following control $(n=5)$ and targeting $(n=3-5)$ ASO treatment in WT islets assessed via $\mathrm{qPCR}$. Insulin secretion in the targeted islets, Cask ASO-treated $(n=17$ mice), compared with control ASO-treated ( $n=11$ mice). $(C)$ RefSeq transcripts depict the "long" and "short" (i.e., skipping exon 26) isoforms of Madd. Exon 26 encodes amino acids 1287-1308, which InterPro annotates as part of a disordered region 58 amino acids upstream of its C-terminal death domain. Sashimi plots of the differentially spliced Madd gene in Bmal1 ${ }^{-/-}$and $\mathrm{Clock}^{-/} \beta$-cell lines. (D) Expression of Madd skipped exon 26 or nontargeted exon 3 in WT $(n=7)$ and Bmal1 ${ }^{-1-}(n=6) \beta$-TC6 cells and following control $(n=5)$ and targeting $(n$ $=4$ ) ASO treatment in WT islets assessed via qPCR. Insulin secretion in the targeted islets, Madd ASO-treated ( $n=15$ mice) compared with control ASO-treated ( $n=9$ mice). 
Alterations in both transcription and alternative splicing of Snap25a in circadian mutant and WT $\beta$ cells

Analysis of RNA-seq by rMATS of circadian mutant cells revealed that Snap25 was one of the few genes that was both differentially expressed $(74 \%$ and $54 \%$ reduction in mRNA in Bmal1 ${ }^{-/-}$and Clock $^{-/-}$cells, respectively, compared with controls) and spliced (MXE: 15\% and $25 \%$ reduced inclusion of alternative exon $5 \mathrm{~b}$ versus $5 \mathrm{a}$ in Bmal1 ${ }^{-1-}$ and Clock $^{-/-}$cells) (Fig. 2A,C,D; Supplemental Figs. S5D, S8A). Since SNAP25 is a key component of the core SNARE complex that mediates stimulus-dependent release of insulin from pancreatic $\beta$ cells and overall expression levels were reduced in circadian mutant $\beta$ cells, we first tested whether overexpression of either of the two major splice-variant isoforms of SNAP2 5 could restore secretion in clock mutant $\beta$ cells. We generated stable Bmal1 ${ }^{-/-}$and WT $\beta$-TC6 cell lines overexpressing fulllength human Snap25a or Snap25b cDNAs, which were validated by qPCR and Western blot (Supplemental Fig. S8B). Surprisingly, overexpression of the Snap25a isoform, which was more abundant relative to Snap25b in clock mutant cells, restored glucose-stimulated insulin secretion in $\mathrm{Bmal1}^{-/-}$cells to levels similar to the ones observed in WT controls (Supplemental Fig. S8B). However, overexpression of the Snap25b did not rescue insulin secretion in the $\mathrm{Bmal1}^{-/-}$cells despite high levels of overexpression (Supplemental Fig. S8B). Overexpression of either Snap25a or Snap25b above endogenous levels in WT cells did not alter insulin secretion, indicating that reduced transcription of Snap25, as opposed to reduced AS-mediated selection of the Snap25b isoform in $B$ mal1 ${ }^{-1-} \beta$ cells, contributes to impaired insulin secretion. To next test whether loss of either the Snap25a or Snap25b isoforms per se was associated with altered GSIS independently from differences in underlying transcription, we used ASOs to block inclusion of alternative exon $5 \mathrm{a}$ or $5 \mathrm{~b}$ and observed $90 \%$ and $83 \%$ reduction in exons $5 \mathrm{a}$ and $5 \mathrm{~b}$, respectively (Supplemental Fig. S8C). Importantly, ASO treatment did not alter the total transcript abundance of either isoform. We observed that loss of the Snap25a transcript resulted in a $78 \%$ reduction in insulin secretion in WT islets, while loss of the Snap25b isoform did not decrease the insulin response (Supplemental Fig. S8C). Thus, our studies suggest that reduced overall Snap25 expression levels, as opposed to reduced inclusion of alternative exon $5 \mathrm{~b}$, contribute to impaired insulin secretion in clock mutant $\beta$ cells.

\section{Diet-induced obesity and circadian disruption impair shared exocytic pathways that are controlled by AS}

Having established that rhythmic AS impacts key regulators of exocytosis in circadian mutant conditions, we sought to determine whether impaired AS might represent a more general defect associated with $\beta$-cell failure in the setting of type 2 diabetes. To determine whether impaired alternative pre-mRNA splicing might occur under conditions of $\beta$-cell disruption in type 2 diabetes and/ or obesity, we analyzed existing deep RNA sequencing data from islets isolated from high-fat diet (HFD)-fed compared with regular chow-fed mice $\left(\mathrm{CON}_{;}>100\right.$ million reads per sample; GSE92602) (Motterle et al. 2017). Principle component analysis (PCA) clustering revealed that AS events in islets from HFD-fed mice segregate from control-fed mice (Supplemental Fig. S9A). Furthermore, we detected 259 differential AS slice events, including 170 SEs, 30 MXEs, 27 A5SS, and 32 A3SS, among 228 unique genes $(\Delta \psi>0.10, P<0.05)$ (Supplemental Fig. S9B; Supplemental Table S5), while there were 187 genes differentially expressed $\left(\log _{2} \mathrm{FC}>1, \mathrm{FDR}<0.05\right)$. Interestingly, similar to the clock mutant islets, there was little overlap between differentially spliced and differentially expressed genes in the islets from HFD-fed mice $(2.6 \%)\left(\log _{2} \mathrm{FC}>1\right.$, FDR $<0.05$ ). Of particular interest, the ortholog of the recently identified type II diabetes risk gene PAM (Thomsen et al. 2018) in humans was one of the most differentially spliced transcripts in the islets from HFD-fed mice (Supplemental Fig. S9B) despite similar total Pam expression in these data. This further provides evidence toward splicing as an inherent regulatory mechanism through which $\beta$-cell function is mediated. To elucidate how these dietinduced changes in RNA processing intersect with circadian control, we next examined the overlap between AS events significantly altered in islets following HFD compared with those altered in the Bmal1 ${ }^{-/-}$cell lines $(\Delta \psi\rangle$ $0.10, P<0.05)$. Surprisingly, we found a $15.8 \%$ overlap (36 out of 228 AS HFD genes) between the two groups, including in the TATA-binding protein (Tbp), the guanine nucleotide-binding protein (G protein; Gnas), and myosin5 (Myo5), and pathway analyses revealed that the most enriched pathways at the intersection of HFD-induced and circadian-regulated splicing act to control membrane protein trafficking and vesicle transport (Supplemental Fig. S9C,D). Overall, the differential AS events were over-represented in gene ontology terms related to synaptic vesicle transport and peptide secretion (Supplemental Fig. S5B).

\section{Discussion}

Mounting evidence from genomic analyses has established extensive circadian control in the expression of tissue-specific gene networks central to metabolism (Koike et al. 2012; Remsberg et al. 2017; Yeung et al. 2018). Most studies have focused on using mRNA- and nascent RNA sequencing in tandem with assays for measuring TF binding to understand the role of the molecular clock in initiating RNA synthesis (Fang et al. 2014; Zhang et al. 2014). More recent ribosome-associated RNA sequencing and proteomics have demonstrated that rhythmicity and phase in circadian transcription does not necessarily reflect final protein expression, particularly outside of the core circadian activator and repressor proteins (Deery et al. 2009; Jang et al. 2015; Janich et al. 2015). Emergence of clock function has been implicated in $\beta$-cell maturation (Alvarez-Dominguez et al. 2020), and circadian control of splicing events are necessary for the proper assembly of synaptic machinery in developing 
neurons (Song et al. 2017; Wang et al. 2018). Despite this link between the circadian clock and neuronal cell-specific splicing, whether the circadian clock mediates AS across the 24-h cycle in peripheral tissues remains incompletely understood.

Here we identified pre-mRNA alternative splicing as an output of the molecular clock that contributes to insulin secretion in pancreatic $\beta$ cells. We also showed that disrupted AS of key exocytic genes following circadian disruption contributes to impaired $\beta$-cell function. Our analyses of RNA sequencing coverage of splice junctions demonstrated extensive modulation of the circadian transcriptome in islets at the level of mRNA isoform selection, and that genes encoding proteins mediating exocytosis, synaptic transmission, and transcription are rhythmically alternatively spliced (Fig. 1; Supplemental Fig. S1). Global splicing patterns further indicated that a majority of splicing events involve retention or exclusion of individual cassette exons (SE), and that these splicing events display a bimodal distribution across the circadian cycle, peaking at times corresponding roughly to the zenith and nadir of endogenous clock-driven insulin secretion (Fig. 1; Supplemental Fig. S1). Our observations suggest that the molecular clock within pancreatic $\beta$ cells regulates insulin secretion by ensuring appropriate mRNA isoform selection at specific phases throughout the day/night cycle.

Since the functional consequences of clock gene manipulation to date have largely been performed in primary murine and human pancreatic islets containing mixed endocrine cell types, our analyses of clonal Bmal1 and Clock knockout $\beta$-cell lines enabled the interrogation of clockdependent transcriptional and AS events associated with impaired insulin secretion in pure populations of insulin-secreting cells (Fig. 2; Supplemental Fig. S2). Genetic depletion of Bmal1 and Clock resulted in phenotypic changes comparable with those observed in pancreas-specific knockout mouse models, such as refractory secretory responses to both glucose and nonnutrient insulin secretagogues (Fig. 2; Supplemental Figs. S2-S4). Moreover, electrophysiologic analysis of Bmall mutant $\beta$-cell lines and mouse $\beta$ cells revealed a conserved defect in depolarization-evoked exocytosis (Fig. 2B), localizing the secretory defect to the final stages of insulin granule fusion and peptide release.

The transcriptomes of $\mathrm{Bmal1}^{-/-}$and $\mathrm{Clock}^{-/-} \beta$ cells revealed perturbations in mRNAs involved with peptide secretion and second messenger signals that trigger insulin secretion (Fig. 2A). We detected significant changes in the AS of $\sim 100$ genes, including vesicle membrane components, kinases, GTPases responsible for posttranslational modifications to the secretory apparatus, and plasma membrane proteins that are also important regulators of neuronal maturation and synaptic function (Fig. 2D). A majority of these missplicing events occurred in mRNAs that were not differentially expressed in the circadian mutants, highlighting the importance of clock control of isoform selection throughout the day. Our analyses of oscillating RNA transcripts in synchronized WT islets, synchronized WT and clock deficient $\beta$ cells, and islets from hyperglycemic animals reveal over-representation of genes encoding vesicle trafficking and synaptic proteins. Furthermore, rhythmic- and CLOCK/BMAL1dependent transcriptomes revealed a repertoire of dynamic RBPs that mediate AS. There is evidence for RBPs regulating circadian splicing events (Benegiamo et al. 2018; Wang et al. 2018) and insulin secretion (Juan-Mateu et al. 2017), but little is known about how circadian RBPs and downstream rhythmic RNA processing regulates peripheral tissue function. Here we demonstrated that the circadian RBP THRAP3 regulates cassette exon skipping in $\beta$ cells at transcripts controlling insulin secretion, including Cask (a scaffold for calcium-calmodulin kinase) and Madd (a RAB3 GTPase-activating protein). We show that proper Thrap3 expression is necessary for maintaining exon skipping in Cask and Madd in Bmal1-/- cells. Surprisingly, simply mimicking the SE events found in $\mathrm{Bmal1}^{-/-}$cells in Cask and Madd transcripts was sufficient to suppress glucose-stimulated insulin secretion in WT mouse islets, suggesting that missplicing of mRNAs such as Cask and Madd may contribute to secretory failure with circadian disruption (Fig. 4). It is intriguing to speculate that reduced inclusion of the Cask exon 11 in the circadian mutants leads to altered interactions with key synaptic membrane proteins such as Postsynaptic density protein 95 (PSD-95), Neurexin-1, and Munc-18interacting protein (MINT) (Chetkovich et al. 2002; Mukherjee et al. 2008), in turn impeding vesicle trafficking (Gillespie and Hodge 2013). Further analyses will be required to determine the impact of reduced inclusion of these Cask and Madd exons on vesicle trafficking and calcium signaling within circadian mutant $\beta$ cells. These findings reveal the importance of circadian control of AS of key exocytotic-controlling genes in the maintenance of $\beta$-cell function.

Snap25 was one of only four genes that were both differentially spliced and reduced in expression in both Clock $^{-1-}$ and Bmal1 ${ }^{-1-} \beta$ cells. Snap25 encodes a target membrane SNARE protein critical for synaptic vesicle exocytosis and expresses either of the mutually exclusive exons $5 \mathrm{a}$ or $5 \mathrm{~b}$, which arose as a consequence of an ancestral duplication event (Bark 1993). While both SNAP25a and SNAP25b are capable of assembling functional SNARE complexes in pancreatic $\beta$ cells (Daraio et al. 2017), the relative roles of the Snap25a and Snap25b isoforms are not well understood. We observed reduced expression of both the Snap25a and Snap25b isoforms in the circadian mutant $\beta$ cells, with a greater reduction in the Snap25b isoform relative to the Snap25a isoform (Supplemental Fig. S8). Our findings that Snap25a overexpression enhanced insulin secretion in the circadian mutant $\beta$ cells, and that blocking inclusion of the Snap25a but not Snap25b isoform using ASOs inhibited insulin secretion, together suggests the $\beta$-cell clock modulates both splice isoform selection and transcription of rhythmic genes. Our studies verify the observation that Snap25a, which is a less functional fetal isoform in neurons, is coexpressed with Snap25b in $\beta$ cells and enhances insulin secretion (Gonelle-Gispert et al. 1999; Daraio et al. 2017). Finally, observations that (1) AS of Snap25 and other neuronal 
mRNAs is developmentally regulated (Bark et al. 1995; Johansson et al. 2008; Song et al. 2017) and (2) the emergence of circadian rhythms during human $\beta$-cell maturation coincides with metabolic maturation (AlvarezDominguez et al. 2020), raise the possibility that the circadian control of AS may participate in $\beta$-cell maturation.

It is estimated that AS occurs in $~ 94 \%$ of human genes (Wang et al. 2008) and that up to $30 \%$ of AS occurs in a tissue-specific manner (Pan et al. 2008). We found that circadian disruption and high-fat feeding led to disrupted AS of an overlapping set of vesicle trafficking and exocytic RNA networks in islets (Supplemental Fig. S9), suggesting that AS is perturbed in both circadian- and diet-induced metabolic disease. However, the RNA-binding proteins (RBPs) regulating AS during circadian and metabolic stress have not been identified (Supplemental Tables S1, S3, S4). Here we identified THRAP3 as a key splicing-regulatory RBP important in rhythmic $\beta$-cell physiology. While THRAP3 depletion in clock-deficient cells partially restores cassette exon inclusion, we note that Thrap3 siRNA treated $\mathrm{Bmal1}^{-/-}$cells still displayed reduced cassette exon inclusion levels relative to WT cells and Thrap3 knockdown did not affect all differentially spliced transcripts, such as Dctn1. Therefore, it is likely that a synergistic relationship exists between clock-controlled and rhythmic RBPs (Supplemental Fig. S5G). We observed that $\alpha$ and $\beta$ cells exhibit cell type-specific patterns in AS across the 24-h timescale (Fig. 2E). Therefore, it remains a possibility that cell type-specific phases of TF recruitment and rates of transcription may be key to understanding how RBPs are targeted on a circadian timescale. The role of transcriptional regulators in RBP recruitment (Supplemental Tables S1, S3, S4) and the mechanisms by which AS is directed by RBPs in pancreatic $\beta$ cells remains incompletely understood. Antisense oligonucleotide therapies currently exist for neuromuscular diseases caused by missplicing, such as spinal muscular atrophy (Hua et al. 2011; Passini et al. 2011), and new chemistries now enable the delivery of ASOs specifically to the $\beta$ cell (Ämmälä et al. 2018). A greater understanding of the molecular mechanisms underlying abnormally spliced transcripts will shed light on therapies for disorders of circadian disruption, including type 2 diabetes.

\section{Materials and methods}

Animals

Male WT C57BL/6J mice were purchased from the Jackson Laboratory. PdxCre;Bmal1 ${ }^{f l x / f l x}$ mice (Marcheva et al. 2010) were produced and maintained on a C57BL/6J background at the Northwestern University Center for Comparative Medicine. $C l o c k^{f l x / f l x}$ mice were crossed with $P d x C r e$ transgenic mice (kindly provided by Dr. David R. Weaver, University of Massachusetts Medical School, and Dr. Douglas Melton, Harvard University, respectively) to generate PdxCre;Clock ${ }^{f l / f l x}$ mice, as well as Clock $^{f l x / f l x}$ and PdxCre littermate controls $(\mathrm{Gu}$ et al. 2002; Debruyne et al. 2006). Offspring from this cross were on a mixed B6x129xICR background. Unless otherwise stated, mice were maintained on a 12:12 light/:dark (LD) cycle and allowed free access to regular chow and water. All animal care and use proce- dures were conducted in accordance with regulations of the Institutional Animal Care and Use Committee at Northwestern University.

\section{$\beta$-TC6 cell culture}

$\beta$-TC6 cells were purchased from ATCC (CRL-11506) and cultured in Dulbecco's modified Eagle's medium (DMEM; Gibco) supplemented with 15\% FBS (Atlanta Biologicals), 1\% L-glutamine (Gibco), and 1\% penicillin/streptomycin (Gibco). All cells used in experiments were at $<15$ passages. For synchronization and knockdown experiments WT and $\mathrm{Bmal1}^{-/-}$cells were plated at $2.5 \times 10^{5}$ cells per well on 24 -well plates. For siRNA treatment, 10 pmol of nontargeting control siRNA (Dharmacon D-00181010-05) or Thrap3 Silencer Select siRNA (Thermo Fisher Scientific 4390771) in Lipofectamine (1.5 $\mu \mathrm{L} /$ well), and Opti-MEM medium (300 $\mu \mathrm{L} /$ well) were first added to 24 -well plates followed by addition of $2.5 \times 10^{5}$ cells in $1 \mathrm{~mL}$ of normal medium. RNA was collected $72 \mathrm{~h}$ later with TRI reagent. For synchronization cells were plated given a $10 \mu \mathrm{M}$ forskolin shock for $1 \mathrm{~h}$, followed by warm PBS wash and medium change to $5 \%$ FBS supplemented DMEM. Cells were collected between 24 and $44 \mathrm{~h}$ later with TRI reagent.

\section{CRISPR-mediated Bmall and Clock deletion in $\beta$-TC6 cell culture}

Exon 8 of Bmal1 and exons 6 and 7 of Clock were deleted in $\beta$-TC6 cells by CRISPR-Cas9 and homology-directed repair (HDR). For Bmal1, intronic DNA flanking Bmal1 exon 8 was cloned into pTOPO2.1 (pBmall-HR) (Invitrogen), and cells were cotransfected with guide RNA, Cas9 [pSpCas9(BB)-2A-Puro; Addgene], and pBmall-HR plasmids. Stably integrated clones were selected for neomycin resistance (G418, Mediatech), and single colonies were hand picked and cultured individually. RNA and protein were extracted from these colonies and Bmal1 mRNA and protein were assessed by qPCR and Western blot. For Clock, cells were cotransfected with guide RNA, Cas9 (Clock CRISPR/Cas9 KO plasmids; Santa Cruz Biotechnology), and Clock HDR plasmids (Santa Cruz Biotechnology sc-419693-HDR). Stably integrated clones were selected for puromycin resistance (puromycin dihydrochloride, Sigma-Aldrich), and single colonies were hand picked and cultured individually. RNA and protein were extracted from these colonies and Clock mRNA and protein were assessed by qPCR and Western blot.

Bioluminescence monitoring in Bmall ${ }^{-/-}$and $\mathrm{Clock}^{-/-} \beta$-cell lines

$\beta$-TC6 WT, Bmal1-/-, and Clock ${ }^{-/-}$cells were infected with a lentivirus expressing a Per2-dLuc reporter construct (gift from A. Liu, University of Memphis) (Liu et al. 2008) and maintained in DMEM with $10 \%$ FBS and $2.5 \mu \mathrm{g} / \mathrm{mL}$ blastocidin (Sigma) to select for stable Per2-dLuc integration. Sealed cell cultures were incubated in $1.2 \mathrm{~mL}$ of DMEM containing $352.5 \mu \mathrm{g} / \mathrm{mL}$ sodium bicarbonate (Gibco), $10 \mathrm{mM}$ HEPES (Gibco), $2 \mathrm{mM}$ L-glutamine, $1 \%$ FBS, $1 \%$ penicillin/streptomycin, $1 \%$ sodium pyruvate (Corning), and $0.1 \mathrm{mM}$ luciferin sodium salt (Biosynth AG). Cultures were placed in a LumiCycle luminometer (Actimetrics), temperature was synchronized for $24 \mathrm{~h}$ (sine wave: $37^{\circ} \mathrm{C}-41^{\circ} \mathrm{C}-$ $37^{\circ} \mathrm{C}-33^{\circ} \mathrm{C}-37^{\circ} \mathrm{C}$, and plates were then maintained at $37^{\circ} \mathrm{C}$. Bioluminescence was recorded continuously for several days.

\section{Glucose and insulin measurements}

Blood glucose and plasma insulin levels in ad libitum-fed mice were assessed at ZT2 and ZT14 from tail vein bleeds. Glucose 
tolerance tests were performed in mice that were first fasted for $14 \mathrm{~h}$. Blood glucose and insulin levels were measured at the indicated times following intraperitoneal (IP) injection of glucose (2 or $3 \mathrm{~g} / \mathrm{kg}$ body weight, as indicated). Plasma insulin levels were measured by ELISA (Crystal Chem, Inc.).

\section{Pancreatic islet and cell line insulin secretion assays}

Pancreatic islets were isolated via bile duct collagenase digestion (Collagenase P, Sigma) and Biocoll (Millipore) gradient separation and left to recover overnight at $37^{\circ} \mathrm{C}$ in RPMI 1640 with $10 \%$ FBS, $1 \%$ L-glutamine, and $1 \%$ penicillin/streptomycin. For insulin release assays, five equally sized islets per mouse (in duplicate) were statically incubated in Krebs-Ringer buffer the following morning ( ZT6) and stimulated for $1 \mathrm{~h}$ at $37^{\circ} \mathrm{C}$ with 2 or $20 \mathrm{mM}$ glucose or $30 \mathrm{mM} \mathrm{KCl}$. Supernatant was collected and assayed for insulin content by ELISA. Islets were then sonicated in acid-ethanol solution and solubilized overnight at $4^{\circ} \mathrm{C}$ before assaying total insulin content by ELISA. Percent insulin content secreted as a response to stimulus was normalized to basal secretion levels for each condition and reported as fold change from control. For insulin release assays in cell lines, $3-4 \times 10^{6}$ cells were cultured for $3 \mathrm{~d}$ in $6-\mathrm{cm}$ suspension culture dishes. Formed pseudoislets were then transferred into new suspension culture media and left to recover overnight. Glucose-responsive insulin secretion was performed as described above, using 10 pseudoislets per sample and a basal glucose level of $0 \mathrm{mM}$ glucose instead of $2 \mathrm{mM}$.

\section{Immunohistochemistry}

Mice were anesthetized with IP injection of phenobarbital (50 $\mathrm{mg} / \mathrm{mL}$; Nembutal) and perfused with heparinized saline, followed by $4 \%$ paraformaldehyde (Sigma) in PBS. Pancreata were removed, postfixed with $4 \%$ PFA overnight at $4^{\circ} \mathrm{C}$ embedded in paraffin, and blocks of $6-\mu \mathrm{m}$ sections were mounted on slides. The following primary antibodies were used for staining: guinea pig anti-insulin (1:500; DAKO), mouse antiglucagon (1:500; Sigma), and rabbit anti-CLOCK (1:500; Millipore). Secondary antibodies included AMCA goat antiguinea pig (1:400; Jackson ImmunoResearch), Alexa fluor 488-conjugated goat antimouse (1:400, Invitrogen), and Alexa flour 546-conjugated goat antirabbit (1:400; Life Technologies). Images were acquired with PictureFrame 1.0 using a Zeiss Axioskop 50.

\section{MRI measurements}

Body composition of live mice was determined by quantitative NMR. Data were analyzed using software by EchoMRI technology (Echo Medical Systems). Fat and lean mass was reported as percentage of body weight.

\section{Activity and feeding measurements}

Locomotor activity was monitored in 2- to 4-mo-old pancreasspecific Clock knockout mice and their respective littermate controls. All animals were individually housed in standard mouse cages equipped with infrared sensors and allowed free access to food and water. Mice were placed in a 12:12 LD cycle for $15 \mathrm{~d}$, followed by $15 \mathrm{~d}$ in constant darkness (DD). Total activity counts were quantified as the total number of infrared sensor beam breaks (Chronobiology kit, Stanford Software Systems). Activity data were analyzed in 6-min bouts using ClockLab software (Actimetrics). The free-running period was determined as the duration of time between the major activity periods on consecutive days. Period was calculated using a $\chi^{2}$ periodogram for days 20-30 (Sokolove and Bushell 1978). Daytime and nighttime food consumption of individually housed animals with free access to water and regular chow was determined by manual measurement of remaining diet at both ZT0 and ZT12 for five consecutive days.

\section{RNA isolation for qPCR mRNA quantification}

Islets or cells were treated with TRI reagent (Sigma Aldrich) and frozen at $-80^{\circ} \mathrm{C}$. RNA was isolated according to the manufacturer's protocol and purified using RNeasy columns (Qiagen). cDNAs were then synthesized using the high-capacity cDNA reverse transcription kit (Applied Biosystems). Real-time quantitative polymerase chain reaction (qPCR) analysis was performed using SYBR Green master mix (Applied Biosystems) and analyzed using an Applied Biosystems 7900 Fast real-time PCR system. Relative expression levels were determined using the comparative CT method to normalize target gene mRNA to $\beta$-actin. Exon-specific primer sequences for qPCR are listed in Supplemental Table S6.

\section{RNA isolation, library preparation, and RNA sequencing}

CRISPR-edited and control cell lines $\left(1 \times 10^{6}\right.$ to $\left.2 \times 10^{6}\right)$ were harvested from six-well plates in triplicate in TRI reagent (Sigma Aldrich), and RNA was isolated using Direct-zol miniprep columns (Zymo) according to the manufacturer's specifications. mRNA libraries for Illumina sequencing were prepared using poly(A) mRNA magnetic isolation module and NEBNext Ultra II directional RNA library kits (New England Biolabs) from $250 \mathrm{ng}$ of total RNA. Libraries were sequenced on an Illumina Nextseq 500 instrument to a minimum of $2 \times 10^{7}$ paired-end 75 -bp reads. Raw sequencing reads were mapped to the $\mathrm{mm} 10$ genome using annotations from the gencode vM10 assembly with STAR version 2.5.0 (Dobin et al. 2013) using default parameters. Individual transcripts annotated in the gencode vM10 assembly were quantified using featureCounts version 1.5.3 (Liao et al. 2014) and the option "-t exon" was specified to count mRNA features.

\section{Differential expression and splicing analyses}

For differential mRNA expression, DESeq2 (version 1.22.1) (Love et al. 2014) analysis was performed on control, Bmal1, and Clock knockout cell lines specifying a false discovery cutoff of 0.01 for independent filtering. Differentially expressed transcripts were defined as having a minimum of $\log _{2}$ fold change value $>1$ and false discovery rate-adjusted $P$-value $<0.01$. For alternative splicing analyses, rMATS (version 4.0.2) (Shen et al. 2014) was used to identify AS events by quantifying exon-exon junction spanning reads on annotated splice junctions present in the mouse gencode vM10 assembly. Differentially spliced mRNAs were defined as having a false discovery rate of $<0.05$ and a minimum inclusion level difference $>10 \%$.

\section{Antisense oligonucleotide experiments}

Phosphorodiamidate morpholino antisense oligonucleotides (ASOs) were designed according to described guidelines (GeneTools) and synthesized as 25-mer vivo morpholinos by GeneTools. ASOs were resuspended in ultrapure water to stock concentration of $0.5 \mathrm{mM}$. Specific sequences and their exon targets are listed in Supplemental Table S6. A nontargeting vivo morpholino ASO standard control was purchased from GeneTools and used at final concentrations matching those of targeting ASOs. WT islets were incubated for $4 \mathrm{~h}$ in $5 \%$ serum 
medium with ASOs for Madd $(5 \mu \mathrm{M})$ and Cask $(2.5 \mu \mathrm{M})$, and were then transferred to normal culture medium for $24 \mathrm{~h}$ before RNA collection or GSIS experiments. For Snap25 experiments, islets were incubated for $24 \mathrm{~h}$ in $5 \%$ serum medium with ASOs for Snap25a or Snap25b (1 $\mu \mathrm{M})$ before RNA collection or GSIS.

\section{Snap25 exon overexpression}

WT and Bmal1-/- $\beta$-TC6 cells were infected with lentivirus expressing either control vector or the complete ORF of the human Snap25a or Snap25b gene (OriGene PS100092V5, RC202068L3V, and RC212596L3V). Stably integrated clones were selected for puromycin resistance (Sigma) and assayed for Snap25a/b mRNA and SNAP25 total protein levels.

\section{Western blotting}

Whole-cell lysates were isolated by treating cell pellets with RIPA buffer (Sigma) containing $1 \times$ protease and $1 \times$ phosphatase inhibitors (Roche). Protein levels were quantified using DC protein assay (Bio-Rad). Protein extracts were then subject to SDS-PAGE gel electrophoresis and transferred to nitrocellulose (GE Healthcare) or Immobilin-P transfer membrane (Millipore). Primary antibodies used were $\beta$-ACTIN (CST 4970), BMAL1 (Santa Cruz Biotechnology sc-48790), CLOCK (Santa Cruz Biotechnology sc-25361), and SNAP25 (CST D9A12).

\section{Patch-clamp electrophysiology}

Patch-clamp measurement of exocytotic responses in single $\beta$ TC6, or mouse $\beta$ cells, was performed at $32^{\circ} \mathrm{C}-35^{\circ} \mathrm{C}$ using the standard whole-cell technique with the sine + DC lock-in function of a HEKA EPC10 amplifier and PatchMaster software (HEKA Electronics). $\beta$-TC6 cells were preincubated in $0 \mathrm{mM}$ glucose EC solution for $1 \mathrm{~h}$, patch-clamped, stimulated with a train of 10 depolarization steps, and the cumulative capacitance was recorded at $20 \mathrm{mM}$ glucose extracellular (EC) solution. Mouse islets were dispersed by shaking in cell dissociation buffer (Gibco, Thermo Scientific) and plated in $35-\mathrm{mm}$ culture dishes. $\beta$ Cells were identified by cell size and sodium channel inactivation at $-90 \mathrm{mV}$ following the experiment, as previously described (Dai et al. 2012). Islet cells were preincubated at $2.8 \mathrm{mM}$ glucose EC for $1 \mathrm{~h}$ and capacitance was measured at $10 \mathrm{mM}$ glucose as described above. The pipette solution for depolarization-stimulated capacitance measurements contained $125 \mathrm{mmol} / \mathrm{L}$ Cs-glutamate, $10 \mathrm{mmol} / \mathrm{L} \mathrm{CsCl}, 10 \mathrm{mmol} / \mathrm{L} \mathrm{NaCl}, 1 \mathrm{mmol} / \mathrm{L} \mathrm{MgCl}_{2} 6 \mathrm{mmol} / \mathrm{L}$ $\mathrm{H}_{2} \mathrm{O}, 0.05 \mathrm{mmol} / \mathrm{L}$ EGTA, $5 \mathrm{mmol} / \mathrm{L}$ HEPES, $0.1 \mathrm{mmol} / \mathrm{L} \mathrm{cAMP}$, and $3 \mathrm{mmol} / \mathrm{L} \mathrm{Mg} \mathrm{ATP} \mathrm{(pH} 7.15$ with $\mathrm{CsOH}$ ). The extracellular bath contained $118 \mathrm{mmol} / \mathrm{L} \mathrm{NaCl}, 20 \mathrm{mmol} / \mathrm{L}$ tetraethylammonium chloride, $5.6 \mathrm{mmol} / \mathrm{L} \mathrm{KCl}, 1.2 \mathrm{mmol} / \mathrm{L} \mathrm{MgCl}_{2} 6 \mathrm{mmol} / \mathrm{L}$ $\mathrm{H}_{2} \mathrm{O}, 2.6 \mathrm{mmol} / \mathrm{L} \mathrm{CaCl} 2,5 \mathrm{mmol} / \mathrm{L}$ glucose, and $5 \mathrm{mmol} / \mathrm{L}$ HEPES (pH 7.4 with $\mathrm{NaOH}$ ). Patch pipettes, pulled from borosilicate glass and coated with Sylgard, had a resistance of 3-4 M $\Omega$ when filled with pipette solution; liquid junction potentials were corrected as appropriate. Quantification of the average cumulative increase in the capacitance of 500-msec depolarizations from -70 to $0 \mathrm{mV}$ was calculated. Measurements were normalized to initial cell size and expressed as femtofarad per picofarad $(\mathrm{fF} / \mathrm{pF})$. Data analysis was performed using GraphPad Prism (v7.0c). Comparison of multiple groups was done by one- or two-way ANOVA followed by Bonferroni or Tukey posttest. Data are expressed as means \pm SEM, where $P<0.05$ is considered significant.

\section{ChIP sequencing and analysis}

Approximately $1 \times 10^{7}$ cells per replicate were collected and processed for ChIP-seq as published previously (Perelis et al. 2015). Briefly, cells were fixed on $15-\mathrm{cm}$ plates in $2 \mathrm{mM}$ disuccinimidyl glutarate in PBS + 1\% DMSO for $30 \mathrm{~min}$, followed by formaldehyde (1\% in PBS) cross-linking for $10 \mathrm{~min}$, followed by quenching with addition of glycine to a total concentration of $125 \mathrm{mM}$ glycine. Cells pellets were collected and frozen at $-80^{\circ} \mathrm{C}$. Crosslinked pellets were twice disrupted by five passages through a needle and syringe in buffer $(150 \mathrm{mM} \mathrm{NaCl}, 5 \mathrm{mM}$ EDTA at $\mathrm{pH}$ $8,50 \mathrm{mM}$ Tris- $\mathrm{HCl}$ at $\mathrm{pH} 8,0.35 \% \mathrm{NP}-40$ ) in the presence of Roche Mini EDTA-free protease inhibitor cocktail and spun at $600 \mathrm{rcf}$ for $5 \mathrm{~min}$. Rough nuclear pellets were sheared in $1 \mathrm{~mL}$ of shearing buffer ( $1 \%$ SDS, $2.5 \mathrm{mM}$ EDTA at $\mathrm{pH} 8,50 \mathrm{mM}$ Tris- $\mathrm{HCl}$ at $\mathrm{p} \mathrm{H}$ 8) in a Diagenode sonicator for 10 high-power cycles $30 \mathrm{sec}$ on $/ 30 \mathrm{sec}$ off at $4^{\circ} \mathrm{C}$. An aliquot for input samples was taken after shearing. Sheared chromatin was diluted 1:10 in dilution buffer $(0.01 \%$ SDS, $1.1 \%$ Triton X-100, $167 \mathrm{mM} \mathrm{NaCl}$, $1.2 \mathrm{mM}$ EDTA at $\mathrm{pH} 8,1.67 \mathrm{mM}$ Tris- $\mathrm{HCl}$ at $\mathrm{pH} 8)$ and $10 \mu \mathrm{g}$ of anti-THRAP3 antibody (NB100-40848) was added and gently rocked overnight at $4^{\circ} \mathrm{C}$. Secondary antirabbit Dynabeads beads were preblocked in $0.1 \%$ BSA and used to pull down antibodybound chromatin, followed by chromatin decross-linking and purification by Qiagen MinElute and library preparation with NEBNext Ultra II library preparation kit for IP and input. Following selection of Sage Pippin PrepHT for adapter-ligated fragments between 200- and 600-bp libraries were amplified for a total of $11 \mathrm{cy}$ cles, cleaned using $0.9 \times$ Ampure XP bead size selection, quantified by Qubit, analyzed for base pair size and quality by Agilent Bioanalyzer, and pooled for sequencing on an Illumina Nextseq 500 instrument with 75-bp single-end reads with $>17$ million unique reads aligned per sample. Reads were aligned with Bowtie2 (v2.2.4) to the mm10 genome with default parameters. Peaks were identified for each IP over pooled input for each genotype using HOMER findPeaks command with setting -style factor. Motif enrichment for ChIP peaks and gene lists promoters was performed using the command findMotifGenome.pl and findMotifs.pl, respectively, and percent enrichment scores versus background plotted in $\mathrm{R}$ using ggplot 2 .

\section{eCLIP sequencing and analysis}

eCLIP was performed as described previously (Van Nostrand et al. 2016) with minor modifications. Approximately $4 \times 10^{7}$ cells per replicate were cross-linked to preserve protein-RNA complexes by UV irradiation $\left(254 \mathrm{~nm}, 400 \mathrm{~mJ} / \mathrm{cm}^{2}\right)$ and cell pellets were harvested in PBS and snap-frozen. Cross-linked cells were lysed in iCLIP lysis buffer $(50 \mathrm{mM}$ Tris- $\mathrm{HCl}$ at $\mathrm{pH} 7.4,100 \mathrm{mM} \mathrm{NaCl}$, $1 \%$ NP-40, $0.1 \%$ SDS, $0.5 \%$ sodium deoxycholate, $1: 200$ protease inhibitor cocktail III) supplemented with 440 units of murine RNAse inhibitor (NEB) and subjected to limited RNase 1 digestion (Ambion) for $5 \mathrm{~min}$ prior to immunoprecipitation with anti-THRAP3 antibody (NB100-40848). Immune complexes were immobilized on magnetic beads (M-280 sheep antirabbit IgG Dynabeads, Thermo Fisher Scientific) and subjected to stringent washes in high-salt buffer $(50 \mathrm{mM}$ Tris- $\mathrm{HCl}$ at $\mathrm{pH} 7.4,1 \mathrm{M}$ $\mathrm{NaCl}, 1 \mathrm{mM}$ EDTA, $1 \% \mathrm{NP}-40,0.1 \%$ SDS, $0.5 \%$ sodium deoxycholate) and low-salt buffer (20 mM Tris- $\mathrm{HCl}$ at $\mathrm{pH} 7.4,10 \mathrm{mM}$ $\mathrm{MgCl} 2,0.2 \%$ Tween-20). Following dephosphorylation (FastAP, Thermo Fisher) and T4 PNK treatment (NEB) of protein-bound RNA fragments on magnetic beads, and barcoded RNA adapters were ligated to the $3^{\prime}$ end (T4 RNA Ligase, NEB). Samples were then run on SDS-polyacrylamide protein gels, transferred to nitrocellulose membranes, and a region from 150 to $225 \mathrm{kDa}$ corresponding to THRAP3 and THRAP3-RNA complexes was excised 
and proteinase K-treated (NEB) to isolate RNA. RNA was reversetranscribed with SuperScript III (Thermo Fisher) and treated with ExoSAP-IT (Affymetrix) to remove excess oligonucleotides. A second DNA adapter (containing a random mer of five or 10 random bases at the $5^{\prime}$ end) was ligated to the $3^{\prime}$ end of cDNA fragments (T4 RNA Ligase, NEB). After bead cleanup (Dynabeads MyOne Silane, Thermo Fisher), an aliquot of each sample was first subjected to qPCR /to identify the proper number of PCR amplification cycles), and the remainder was PCR-amplified (Q5, $\mathrm{NEB}$ ) and size-selected via agarose gel electrophoresis. Libraries were sequenced on an Illumina NextSeq500 with 75-bp singleend reads with $>15$ million uniquely mapped reads aligned to the mouse mm10 reference genome per sample using STAR (v2.4.0i). Metagene plots were produced by first extending relevant AS intron and exon chromosomal locations by 50 bp upstream and downstream, followed by quantification of reads per million mapped reads (RPM) across 100 bins using the Metagene package in Rstudio (v3.6.1).

\section{Statistical analysis}

Where appropriate, results were expressed as mean \pm SEM unless otherwise noted. Detailed information on sample size, genotype, and $P$-values can be found within individual figures and figure legends. Statistical analysis was performed by unpaired two-tailed Student's $t$-test unless otherwise indicated. $P<0.05$ was considered to be statistically significant.

Sequencing data availability

RNA-seq, ChIP-seq, and eCLIP-seq data sets have been deposited in the Gene Expression Omnibus server accession number GSE146916.

\section{Competing interest statement}

G.W.Y. is cofounder, member of the Board of Directors, on the Scientific Advisory Board, equity holder, and paid consultant for Locanabio and Eclipse BioInnovations. G.W.Y. is a visiting professor at the National University of Singapore. G.W.Y.'s interest(s) have been reviewed and approved by the University of California at San Diego in accordance with its conflict of interest policies. The authors declare no other competing financial interests.

\section{Acknowledgments}

We thank Dr. David R. Weaver (University of Massachusetts) and Dr. Douglas Melton (Harvard University) for kindly providing Clock $^{f^{\prime} / f l_{x}}$ and PdxCre mice, Ganka Ivanova and Shelley Mo for technical assistance with glucose tolerance tests, Brian Yee for bioinformatics assistance, and all members of the Bass, Barish, Yeo, and MacDonald laboratories for helpful discussions. This work was supported by National Institute of Diabetes and Digestive and Kidney Diseases (NIDDK) grants (R01DK090625, R01DK100814, and 1R01DK113011-01A1), a National Institute on Aging (NIA) grant (P01AG011412), the Chicago Biomedical Consortium (S-007), JDRF grants (17-2013-511, 1-INO-2014178-A-V, and 1-INO-2015-23-A-V), and the University of Chicago Diabetes Research and Training Center (P60DK020595) to J.B.; a NIDDK T32 grant (DK007169) to B.M.; a National Research Service Award (NRSA) grant (F32HL143978) and a National Heart, Lung, and Blood Institute (NHLBI) T32 grant (HL007909) to M.P.; a National Research Service Award (NRSA; grant
F30DK116481) to B.J.W.; a Manpei Suzuki Diabetes Foundation fellowship to A.T.; a National Science Foundation fellowship to E.C.W.; a studentship from the Li Ka Shing Foundation to H.L.; a NIH grant (R01HL061322) to E.M.M.; a Foundation Grant from the Canadian Institutes of Health Research to P.E.M.; and a NIH grant (HG004659) to G.W.Y.

Author contributions: B.M. designed, performed, and analyzed results for all in vivo metabolic testing, in vitro islet treatments, and immunohistochemical and behavioral studies, with technical assistance from M.P., Y.K., C.O., H.H., and M.V.N. M.P. and B.J.W. performed the differential expression, splicing, ChIP-seq, and eCLIP analyses with assistance from E.C.W., A.S., and G.W.Y. C.O. oversaw animal husbandry for pancreas-specific Clock KO mice. A.T. generated the $\mathrm{Bmal1}^{-1-}$ and $\mathrm{Clock}^{-/-}$cell lines and performed bioluminescence and Western blot experiments. H.L., J.E.M.F., and P.E.M. performed and analyzed capacitance experiments. E.J.W. and E.M.M. helped with the ASO experimental design. B.M., M.P., and B.J.W. analyzed all data presentation with guidance from K.M.R. and J.B. B.M., M.P., B.J.W., K.M.R., and J.B. wrote the manuscript.

\section{References}

Alvarez-Dominguez JR, Donaghey J, Rasouli N, Kenty JHR, Helman A, Charlton J, Straubhaar JR, Meissner A, Melton DA. 2020. Circadian entrainment triggers maturation of human in vitro islets. Cell Stem Cell 26: 108-122.e10. doi:10.1016/j .stem.2019.11.011

Ämmälä C, Drury WJ 3rd, Knerr L, Ahlstedt I, Stillemark-Billton P, Wennberg-Huldt C, Andersson EM, Valeur E, Jansson-Löfmark R, Janzén D, et al. 2018. Targeted delivery of antisense oligonucleotides to pancreatic $\beta$-cells. Sci Adv 4: eaat3386. doi:10.1126/sciadv.aat3386

Asher G, Schibler U. 2011. Crosstalk between components of circadian and metabolic cycles in mammals. Cell Metab 13: 125137. doi:10.1016/j.cmet.2011.01.006

Atasoy D, Schoch S, Ho A, Nadasy KA, Liu X, Zhang W, Mukherjee K, Nosyreva ED, Fernandez-Chacon R, Missler M, et al. 2007. Deletion of CASK in mice is lethal and impairs synaptic function. Proc Natl Acad Sci 104: 2525-2530. doi:10.1073/ pnas.0611003104

Balsalobre A, Damiola F, Schibler U. 1998. A serum shock induces circadian gene expression in mammalian tissue culture cells. Cell 93: 929-937. doi:10.1016/S0092-8674|00|81199-X

Barber AF, Erion R, Holmes TC, Sehgal A. 2016. Circadian and feeding cues integrate to drive rhythms of physiology in Drosophila insulin-producing cells. Genes Dev 30: 2596-2606. doi:10.1101/gad.288258.116

Bark IC. 1993. Structure of the chicken gene for SNAP-25 reveals duplicated exons encoding distinct isoforms of the protein. J Mol Biol 233: 67-76. doi:10.1006/jmbi.1993.1485

Bark IC, Hahn KM, Ryabinin AE, Wilson MC. 1995. Differential expression of SNAP-25 protein isoforms during divergent vesicle fusion events of neural development. Proc Nat1 Acad Sci 92: 1510-1514. doi:10.1073/pnas.92.5.1510

Bass J. 2012. Circadian topology of metabolism. Nature 491: 348356. doi:10.1038/nature11704

Bass J, Takahashi JS. 2010. Circadian integration of metabolism and energetics. Science 330: 1349-1354. doi:10.1126/science .1195027

Benegiamo G, Mure LS, Erikson G, Le HD, Moriggi E, Brown SA, Panda S. 2018. The RNA-binding protein NONO coordinates hepatic adaptation to feeding. Cell Metab 27: 404-418.e7. doi:10.1016/j.cmet.2017.12.010 
Bugge A, Feng D, Everett LJ, Briggs ER, Mullican SE, Wang F, Jager J, Lazar MA. 2012. REV-ERB $\alpha$ and REV-ERB $\beta$ coordinately protect the circadian clock and normal metabolic function. Genes Dev 26: 657-667. doi:10.1101/gad.186858.112

Buhr ED, Yoo SH, Takahashi JS. 2010. Temperature as a universal resetting cue for mammalian circadian oscillators. Science 330: 379-385. doi:10.1126/science.1195262

Chetkovich DM, Bunn RC, Kuo SH, Kawasaki Y, Kohwi M, Bredt DS. 2002. Postsynaptic targeting of alternative postsynaptic density-95 isoforms by distinct mechanisms. I Neurosci 22: 6415-6425. doi:10.1523/JNEUROSCI.22-15-06415.2002

Cho H, Zhao X, Hatori M, Yu RT, Barish GD, Lam MT, Chong LW, DiTacchio L, Atkins AR, Glass CK, et al. 2012. Regulation of circadian behaviour and metabolism by REV-ERB- $\alpha$ and REV-ERB- $\beta$. Nature 485: 123-127. doi:10.1038/nature 11048

Choi JH, Choi SS, Kim ES, Jedrychowski MP, Yang YR, Jang HJ, Suh PG, Banks AS, Gygi SP, Spiegelman BM. 2014. THRAP3 docks on phosphoserine 273 of PPAR $\gamma$ and controls diabetic gene programming. Genes Dev 28: 2361-2369. doi:10.1101/ gad.249367.114

Dai XQ, Manning Fox JE, Chikvashvili D, Casimir M, Plummer G, Hajmrle C, Spigelman AF, Kin T, Singer-Lahat D, Kang Y, et al. 2012. The voltage-dependent potassium channel subunit Kv2.1 regulates insulin secretion from rodent and human islets independently of its electrical function. Diabetologia 55: 1709-1720. doi:10.1007/s00125-012-2512-6

Daraio T, Bombek LK, Gosak M, Valladolid-Acebes I, Klemen MS, Refai E, Berggren PO, Brismar K, Rupnik MS, Bark C. 2017. SNAP-25b-deficiency increases insulin secretion and changes spatiotemporal profile of $\mathrm{Ca}^{2+}$ oscillations in $\beta$ cell networks. Sci Rep 7: 7744. doi:10.1038/s41598-017-08082-y

Debruyne JP, Noton E, Lambert CM, Maywood ES, Weaver DR, Reppert SM. 2006. A clock shock: mouse CLOCK is not required for circadian oscillator function. Neuron 50: 465-477. doi:10.1016/j.neuron.2006.03.041

Deery MJ, Maywood ES, Chesham JE, Sládek M, Karp NA, Green EW, Charles PD, Reddy AB, Kyriacou CP, Lilley KS, et al. 2009. Proteomic analysis reveals the role of synaptic vesicle cycling in sustaining the suprachiasmatic circadian clock. Curr Biol 19: 2031-2036. doi:10.1016/j.cub.2009.10.024

Dobin A, Davis CA, Schlesinger F, Drenkow J, Zaleski C, Jha S, Batut P, Chaisson M, Gingeras TR. 2013. STAR: ultrafast universal RNA-seq aligner. Bioinformatics 29: 15-21. doi:10 .1093/bioinformatics/bts635

Fang B, Everett LJ, Jager J, Briggs E, Armour SM, Feng D, Roy A, Gerhart-Hines Z, Sun Z, Lazar MA. 2014. Circadian enhancers coordinate multiple phases of rhythmic gene transcription in vivo. Cell 159: 1140-1152. doi:10.1016/j.cell.2014.10.022

Fustin JM, Doi M, Yamaguchi Y, Hida H, Nishimura S, Yoshida M, Isagawa T, Morioka MS, Kakeya H, Manabe I, et al. 2013. RNA-methylation-dependent RNA processing controls the speed of the circadian clock. Cell 155: 793-806. doi:10.1016/ j.cell.2013.10.026

Gachon F, Olela FF, Schaad O, Descombes P, Schibler U. 2006. The circadian PAR-domain basic leucine zipper transcription factors DBP, TEF, and HLF modulate basal and inducible xenobiotic detoxification. Cell Metab 4: 25-36. doi:10.1016/j .cmet.2006.04.015

Gillespie JM, Hodge JJ. 2013. CASK regulates CaMKII autophosphorylation in neuronal growth, calcium signaling, and learning. Front Mol Neurosci 6: 27. doi:10.3389/fnmol.2013.00027

Gizowski C, Zaelzer C, Bourque CW. 2016. Clock-driven vasopressin neurotransmission mediates anticipatory thirst prior to sleep. Nature 537: 685-688. doi:10.1038/nature19756
Gonelle-Gispert C, Halban PA, Niemann H, Palmer M, Catsicas S, Sadoul K. 1999. SNAP-25a and -25b isoforms are both expressed in insulin-secreting cells and can function in insulin secretion. Biochem J 339: 159-165. doi:10.1042/bj3390159

Gotic I, Omidi S, Fleury-Olela F, Molina N, Naef F, Schibler U. 2016. Temperature regulates splicing efficiency of the coldinducible RNA-binding protein gene Cirbp. Genes Dev 30: 2005-2017. doi:10.1101/gad.287094.116

Green CB. 2018. Circadian posttranscriptional regulatory mechanisms in mammals. Cold Spring Harb Perspect Biol 10: a030692. doi:10.1101/cshperspect.a030692

Gu G, Dubauskaite J, Melton DA. 2002. Direct evidence for the pancreatic lineage: $\mathrm{NGN}^{+}$cells are islet progenitors and are distinct from duct progenitors. Development 129: 2447-2457.

Hua Y, Sahashi K, Rigo F, Hung G, Horev G, Bennett CF, Krainer AR. 2011. Peripheral SMN restoration is essential for longterm rescue of a severe spinal muscular atrophy mouse model. Nature 478: 123-126. doi:10.1038/nature10485

Hughes ME, DiTacchio L, Hayes KR, Vollmers C, Pulivarthy S, Baggs JE, Panda S, Hogenesch JB. 2009. Harmonics of circadian gene transcription in mammals. PLoS Genet 5: e1000442. doi:10.1371/journal.pgen.1000442

Hughes ME, Hogenesch JB, Kornacker K. 2010. JTK_CYCLE: an efficient nonparametric algorithm for detecting rhythmic components in genome-scale data sets. I Biol Rhythms 25: 372-380. doi:10.1177/0748730410379711

Hughes ME, Grant GR, Paquin C, Qian J, Nitabach MN. 2012. Deep sequencing the circadian and diurnal transcriptome of Drosophila brain. Genome Res 22: 1266-1281. doi:10.1101/ gr.128876.111

Jang C, Lahens NF, Hogenesch JB, Sehgal A. 2015. Ribosome profiling reveals an important role for translational control in circadian gene expression. Genome Res 25: 1836-1847. doi:10 $.1101 /$ gr.191296.115

Janich P, Arpat AB, Castelo-Szekely V, Lopes M, Gatfield D. 2015. Ribosome profiling reveals the rhythmic liver translatome and circadian clock regulation by upstream open reading frames. Genome Res 25: 1848-1859. doi:10.1101/gr.195404 .115

Johansson JU, Ericsson J, Janson J, Beraki S, Stanić D, Mandic SA, Wikström MA, Hökfelt T, Ögren SO, Rozell B, et al. 2008. An ancient duplication of exon 5 in the Snap25 gene is required for complex neuronal development/function. PLoS Genet 4: e1000278. doi:10.1371/journal.pgen.1000278

Juan-Mateu J, Rech TH, Villate O, Lizarraga-Mollinedo E, Wendt A, Turatsinze JV, Brondani LA, Nardelli TR, Nogueira TC, Esguerra JL, et al. 2017. Neuron-enriched RNA-binding proteins regulate pancreatic $\beta$ cell function and survival. $J$ Biol Chem 292: 3466-3480. doi:10.1074/jbc.M116.748335

Kim HK, Pham MHC, Ko KS, Rhee BD, Han J. 2018. Alternative splicing isoforms in health and disease. Pflugers Arch 470: 995-1016. doi:10.1007/s00424-018-2136-x

Koike N, Yoo SH, Huang HC, Kumar V, Lee C, Kim TK, Takahashi JS. 2012. Transcriptional architecture and chromatin landscape of the core circadian clock in mammals. Science 338: 349-354. doi:10.1126/science.1226339

Kojima S, Sher-Chen EL, Green CB. 2012. Circadian control of mRNA polyadenylation dynamics regulates rhythmic protein expression. Genes Dev 26: 2724-2736. doi:10.1101/gad .208306 .112

Kurada BR, Li LC, Mulherkar N, Subramanian M, Prasad KV, Prabhakar BS. 2009. MADD, a splice variant of IG20, is indispensable for MAPK activation and protection against apoptosis upon tumor necrosis factor- $\alpha$ treatment. J Biol Chem 284: 13533-13541. doi:10.1074/jbc.M808554200 
Lande-Diner L, Boyault C, Kim JY, Weitz CJ. 2013. A positive feedback loop links circadian clock factor CLOCK-BMAL1 to the basic transcriptional machinery. Proc Natl Acad Sci 110: 16021-16026. doi:10.1073/pnas.1305980110

Lee S, Fan S, Makarova O, Straight S, Margolis B. 2002. A novel and conserved protein-protein interaction domain of mammalian LIN-2/CASK binds and recruits SAP97 to the lateral surface of epithelia. Mol Cell Biol 22: 1778-1791. doi:10 .1128/MCB.22.6.1778-1791.2002

Lee CS, Friedman JR, Fulmer JT, Kaestner KH. 2005. The initiation of liver development is dependent on FOXA transcription factors. Nature 435: 944-947. doi:10.1038/nature03649

Li LC, Wang Y, Carr R, Haddad CS, Li Z, Qian L, Oberholzer J, Maker AV, Wang Q, Prabhakar BS. 2014. IG20/MADD plays a critical role in glucose-induced insulin secretion. Diabetes 63: 1612-1623. doi:10.2337/db13-0707

Liao Y, Smyth GK, Shi W. 2014. featureCounts: an efficient general purpose program for assigning sequence reads to genomic features. Bioinformatics 30: 923-930. doi:10.1093/bioinfor matics/btt656

Liu AC, Tran HG, Zhang EE, Priest AA, Welsh DK, Kay SA. 2008. Redundant function of REV-ERB $\alpha$ and $\beta$ and non-essential role for Bmal1 cycling in transcriptional regulation of intracellular circadian rhythms. PLoS Genet 4: e1000023. doi:10.1371/jour nal.pgen. 1000023

Love MI, Huber W, Anders S. 2014. Moderated estimation of fold change and dispersion for RNA-seq data with DESeq2. Genome Biol 15: 550. doi:10.1186/s13059-014-0550-8

Lowrey PL, Takahashi JS. 2004. Mammalian circadian biology: elucidating genome-wide levels of temporal organization. Annu Rev Genomics Hum Genet 5: 407-441. doi:10.1146/ annurev.genom.5.061903.175925

Marcheva B, Ramsey KM, Buhr ED, Kobayashi Y, Su H, Ko CH, Ivanova G, Omura C, Mo S, Vitaterna MH, et al. 2010. Disruption of the clock components CLOCK and BMAL1 leads to hypoinsulinaemia and diabetes. Nature 466: 627-631. doi:10 $.1038 /$ nature09253

McGlincy NJ, Valomon A, Chesham JE, Maywood ES, Hastings MH, Ule J. 2012. Regulation of alternative splicing by the circadian clock and food related cues. Genome Biol 13: R54. doi:10.1186/gb-2012-13-6-r54

Menet JS, Rodriguez J, Abruzzi KC, Rosbash M. 2012. NascentSeq reveals novel features of mouse circadian transcriptional regulation. Elife 1: e00011. doi:10.7554/eLife.00011

Morf J, Rey G, Schneider K, Stratmann M, Fujita J, Naef F, Schibler U. 2012. Cold-inducible RNA-binding protein modulates circadian gene expression posttranscriptionally. Science 338: 379-383. doi:10.1126/science.1217726

Motterle A, Gattesco S, Peyot ML, Esguerra JLS, Gomez-Ruiz A, Laybutt DR, Gilon P, Burdet F, Ibberson M, Eliasson L, et al. 2017. Identification of islet-enriched long non-coding RNAs contributing to $\beta$-cell failure in type 2 diabetes. Mol Metab 11: 1407-1418. doi:10.1016/j.molmet.2017.08.005

Mukherjee K, Sharma M, Urlaub H, Bourenkov GP, Jahn R, Südhof TC, Wahl MC. 2008. CASK Functions as a $\mathrm{Mg}^{2+}$-independent neurexin kinase. Cell 133: 328-339. doi:10.1016/j.cell .2008 .02 .036

Nakabayashi H, Ohta Y, Yamamoto M, Susuki Y, Taguchi A, Tanabe K, Kondo M, Hatanaka M, Nagao Y, Tanizawa Y. 2013. Clock-controlled output gene $D b p$ is a regulator of Arnt/Hif-1 $\beta$ gene expression in pancreatic islet $\beta$-cells. Biochem Biophys Res Commun 434: 370-375. doi:10.1016/j .bbrc.2013.03.084

Nakatsuru Y, Aoki K, Ishikawa T. 1989. Age and strain dependence of $\mathrm{O}^{6}$-methylguanine DNA methyltransferase activity in mice. Mutat Res 219: 51-56. doi:10.1016/0921-8734(89) 90040-4

Pan Q, Shai O, Lee LJ, Frey BJ, Blencowe BJ. 2008. Deep surveying of alternative splicing complexity in the human transcriptome by high-throughput sequencing. Nat Genet 40: 14131415. doi:10.1038/ng.259

Panda S, Antoch MP, Miller BH, Su AI, Schook AB, Straume M, Schultz PG, Kay SA, Takahashi JS, Hogenesch JB. 2002. Coordinated transcription of key pathways in the mouse by the circadian clock. Cell 109: 307-320. doi:10.1016/S0092-8674(02) 00722-5

Passini MA, Bu J, Richards AM, Kinnecom C, Sardi SP, Stanek LM, Hua Y, Rigo F, Matson J, Hung G, et al. 2011. Antisense oligonucleotides delivered to the mouse CNS ameliorate symptoms of severe spinal muscular atrophy. Sci Transl Med 3: 72ra18. doi:10.1126/scitranslmed.3001777

Perelis M, Marcheva B, Ramsey KM, Schipma MJ, Hutchison AL, Taguchi A, Peek CB, Hong H, Huang W, Omura C, et al. 2015. Pancreatic $\beta$ cell enhancers regulate rhythmic transcription of genes controlling insulin secretion. Science 350: aac4250. doi:10.1126/science.aac4250

Petrenko V, Saini C, Giovannoni L, Gobet C, Sage D, Unser M, Heddad Masson M, Gu G, Bosco D, Gachon F, et al. 2017. Pancreatic $\alpha$ - and $\beta$-cellular clocks have distinct molecular properties and impact on islet hormone secretion and gene expression. Genes Dev 31: 383-398. doi:10.1101/gad.290379 .116

Preitner N, Damiola F, Lopez-Molina L, Zakany J, Duboule D, Albrecht U, Schibler U. 2002. The orphan nuclear receptor REV-ERB $\alpha$ controls circadian transcription within the positive limb of the mammalian circadian oscillator. Cell 110: 251-260. doi:10.1016/S0092-8674(02)00825-5

Preußner M, Goldammer G, Neumann A, Haltenhof T, Rautenstrauch P, Müller-McNicoll M, Heyd F. 2017. Body temperature cycles control rhythmic alternative splicing in mammals. Mol Cell 67: 433-446.e4. doi:10.1016/j.molcel .2017.06.006

Remsberg JR, Ediger BN, Ho WY, Damle M, Li Z, Teng C, Lanzillotta C, Stoffers DA, Lazar MA. 2017. Deletion of histone deacetylase 3 in adult $\beta$ cells improves glucose tolerance via increased insulin secretion. Mol Metab 6: 30-37. doi:10 .1016/j.molmet.2016.11.007

Roh MH, Makarova O, Liu CJ, Shin K, Lee S, Laurinec S, Goyal M, Wiggins R, Margolis B. 2002. The Maguk protein, PALS1, functions as an adapter, linking mammalian homologues of Crumbs and Discs Lost. I Cell Biol 157: 161-172. doi:10 $.1083 /$ jcb. 200109010

Sadacca LA, Lamia KA, deLemos AS, Blum B, Weitz CJ. 2011. An intrinsic circadian clock of the pancreas is required for normal insulin release and glucose homeostasis in mice. Diabetologia 54: 120-124. doi:10.1007/s00125-010-1920-8

Saini C, Morf J, Stratmann M, Gos P, Schibler U. 2012. Simulated body temperature rhythms reveal the phase-shifting behavior and plasticity of mammalian circadian oscillators. Genes Dev 26: 567-580. doi:10.1101/gad.183251.111

Sanchez SE, Petrillo E, Beckwith EJ, Zhang X, Rugnone ML, Hernando CE, Cuevas JC, Godoy Herz MA, Depetris-Chauvin A, Simpson CG, et al. 2010. A methyl transferase links the circadian clock to the regulation of alternative splicing. Nature 468: 112-116. doi:10.1038/nature09470

Shen S, Park JW, Lu ZX, Lin L, Henry MD, Wu YN, Zhou Q, Xing Y. 2014. rMATS: robust and flexible detection of differential alternative splicing from replicate RNA-Seq data. Proc Nat1 Acad Sci 111: E5593-E5601. doi:10.1073/pnas.1419161111 
Shinohara K, Funabashi T, Nakamura TJ, Mitsushima D, Kimura F. 2002. Differential regulation of pituitary adenylate cyclaseactivating peptide receptor variants in the rat suprachiasmatic nucleus. Neuroscience 110:301-308. doi:10.1016/S0306-4522 (01)00479-1

Sokolove PG, Bushell WN. 1978. The chi square periodogram: its utility for analysis of circadian rhythms. I Theor Biol 72: 131-160. doi:10.1016/0022-5193(78)90022-X

Song Y, Botvinnik OB, Lovci MT, Kakaradov B, Liu P, Xu JL, Yeo GW. 2017. Single-cell alternative splicing analysis with expedition reveals splicing dynamics during neuron differentiation. Mol Cell 67: 148-161.e5. doi:10.1016/j.molcel.2017.06 .003

Suckow AT, Comoletti D, Waldrop MA, Mosedale M, Egodage S, Taylor P, Chessler SD. 2008. Expression of neurexin, neuroligin, and their cytoplasmic binding partners in the pancreatic $\beta$-cells and the involvement of neuroligin in insulin secretion. Endocrinology 149: 6006-6017. doi:10.1210/en.2008-0274

Terajima H, Yoshitane H, Ozaki H, Suzuki Y, Shimba S, Kuroda S, Iwasaki W, Fukada Y. 2017. ADARB1 catalyzes circadian Ato-I editing and regulates RNA rhythm. Nat Genet 49: 146151. doi:10.1038/ng.3731

Thomsen SK, Raimondo A, Hastoy B, Sengupta S, Dai XQ, Bautista A, Censin J, Payne AJ, Umapathysivam MM, Spigelman AF, et al. 2018. Type 2 diabetes risk alleles in PAM impact insulin release from human pancreatic $\beta$-cells. Nat Genet 50: 1122-1131. doi:10.1038/s41588-018-0173-1

Tong X, Muchnik M, Chen Z, Patel M, Wu N, Joshi S, Rui L, Lazar MA, Yin L. 2010. Transcriptional repressor E4-binding protein 4 (E4BP4) regulates metabolic hormone fibroblast growth factor 21 (FGF21) during circadian cycles and feeding. I Biol Chem 285: 36401-36409. doi:10.1074/jbc.M110.172866

Tripathi S, Pohl MO, Zhou Y, Rodriguez-Frandsen A, Wang G, Stein DA, Moulton HM, DeJesus P, Che J, Mulder LC, et al. 2015. Meta- and orthogonal integration of influenza 'OMICs' data defines a role for UBR4 in virus budding. Cell Host Microbe 18: 723-735. doi:10.1016/j.chom.2015.11.002

Van Nostrand EL, Pratt GA, Shishkin AA, Gelboin-Burkhart C, Fang MY, Sundararaman B, Blue SM, Nguyen TB, Surka C, Elkins K, et al. 2016. Robust transcriptome-wide discovery of RNA-binding protein binding sites with enhanced CLIP (eCLIP). Nat Methods 13: 508-514. doi:10.1038/nmeth.3810

Vollmers C, Gill S, DiTacchio L, Pulivarthy SR, Le HD, Panda S. 2009. Time of feeding and the intrinsic circadian clock drive rhythms in hepatic gene expression. Proc Natl Acad Sci 106: 21453-21458. doi:10.1073/pnas.0909591106

Vuong CK, Black DL, Zheng S. 2016. The neurogenetics of alternative splicing. Nat Rev Neurosci 17: 265-281. doi:10.1038/ nrn.2016.27

Wang ET, Sandberg R, Luo S, Khrebtukova I, Zhang L, Mayr C, Kingsmore SF, Schroth GP, Burge CB. 2008. Alternative isoform regulation in human tissue transcriptomes. Nature 456: 470-476. doi:10.1038/nature07509

Wang Y, Lin H, Hao N, Zhu Z, Wang D, Li Y, Chen H, Zhu Y, Han X. 2015. Forkhead box O1 mediates defects in palmitate-induced insulin granule exocytosis by downregulation of calcium/calmodulin-dependent serine protein kinase expression in INS-1 cells. Diabetologia 58: 1272-1281. doi:10.1007/ s00125-015-3561-4

Wang Q, Abruzzi KC, Rosbash M, Rio DC. 2018. Striking circadian neuron diversity and cycling of Drosophila alternative splicing. Elife 7: e35618.

Yarosh CA, Tapescu I, Thompson MG, Qiu J, Mallory MJ, Fu XD, Lynch KW. 2015. TRAP150 interacts with the RNA-binding domain of PSF and antagonizes splicing of numerous PSF-target genes in T cells. Nucleic Acids Res 43: 9006-9016. doi:10 $.1093 / \mathrm{nar} / \mathrm{gkv} 816$

Yeung J, Mermet J, Jouffe C, Marquis J, Charpagne A, Gachon F, Naef F. 2018. Transcription factor activity rhythms and tissue-specific chromatin interactions explain circadian gene expression across organs. Genome Res 28: 182-191. doi:10.1101/ gr.222430.117

Young RA, Hagenbüchle O, Schibler U. 1981. A single mouse aamylase gene specifies two different tissue-specific mRNAs. Cell 23: 451-458. doi:10.1016/0092-8674(81)90140-9

Zhang R, Lahens NF, Ballance HI, Hughes ME, Hogenesch JB. 2014. A circadian gene expression atlas in mammals: implications for biology and medicine. Proc Natl Acad Sci 111: 16219-16224. doi:10.1073/pnas.1408886111 


\section{ERRATUM}

Genes \& Development 34: 1089-1105 (2020)

\section{Erratum: A role for alternative splicing in circadian control of exocytosis and glucose homeostasis}

Biliana Marcheva, Mark Perelis, Benjamin J. Weidemann, Akihiko Taguchi, Haopeng Lin, Chiaki Omura, Yumiko Kobayashi, Marsha V. Newman, Eugene J. Wyatt, Elizabeth M. McNally, Jocelyn E. Manning Fox, Heekyung Hong, Archana Shankar, Emily C. Wheeler, Kathryn Moynihan Ramsey, Patrick E. MacDonald, Gene W. Yeo, and Joseph Bass

In the above-mentioned article, the "Competing interest statement" was mistakenly omitted but has now been added to the article online:

"G.W.Y. is cofounder, member of the Board of Directors, on the Scientific Advisory Board, equity holder, and paid consultant for Locanabio and Eclipse BioInnovations. G.W.Y. is a visiting professor at the National University of Singapore. G.W.Y.'s interest(s) have been reviewed and approved by the University of California at San Diego in accordance with its conflict of interest policies. The authors declare no other competing financial interests."

doi: $10.1101 / \operatorname{gad} .348303 .121$ 


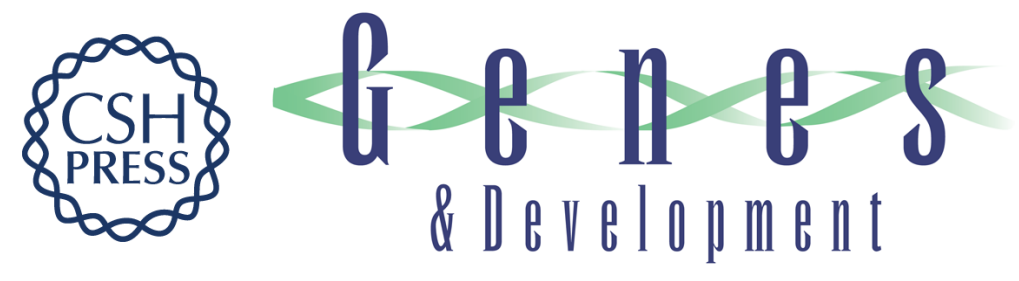

\section{A role for alternative splicing in circadian control of exocytosis and glucose homeostasis}

Biliana Marcheva, Mark Perelis, Benjamin J. Weidemann, et al.

Genes Dev. 2020, 34: originally published online July 2, 2020

Access the most recent version at doi:10.1101/gad.338178.120

\section{Supplemental http://genesdev.cshlp.org/content/suppl/2020/06/30/gad.338178.120.DC1 \\ Material}

Related Content Erratum: A role for alternative splicing in circadian control of exocytosis and glucose homeostasis

Biliana Marcheva, Mark Perelis, Benjamin J. Weidemann, et al.

Genes Dev. March , 2021 35: 425

References This article cites 89 articles, 33 of which can be accessed free at: http://genesdev.cshlp.org/content/34/15-16/1089.full.html\#ref-list-1

Articles cited in: http://genesdev.cshlp.org/content/34/15-16/1089.full.html\#related-urls

Creative This article, published in Genes \& Development, is available under a Creative Commons Commons License (Attribution 4.0 International), as described at License http://creativecommons.org/licenses/by/4.0/.

Email Alerting Receive free email alerts when new articles cite this article - sign up in the box at the top Service right corner of the article or click here.

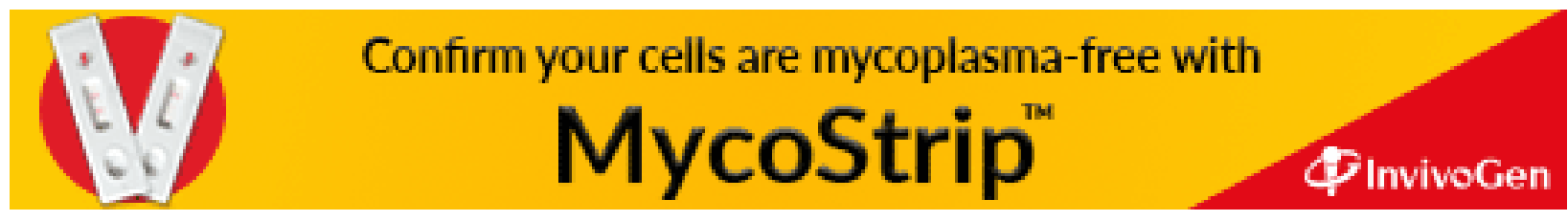

